\title{
Stationary and Nonstationary Ion and Water Flux Interactions in Kidney Proximal Tubule: Mathematical Analysis of Isosmotic Transport by a Minimalistic Model
}

\author{
Erik Hviid Larsen and Jens Nørkær Sørensen
}

\section{Contents}

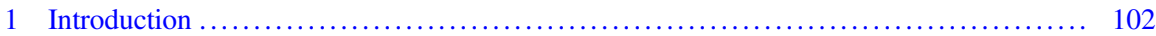

2 Description of the Minimalistic Model ..................................... 104

2.1 Functional Organization of Proximal Tubule Epithelium .................... 104

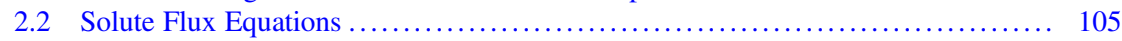

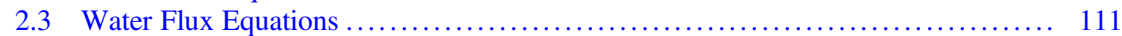

2.4 Compliant Model and Volumes of Intraepithelial Compartments ............... 113

2.5 Electrical-Circuit Analysis ........................................... 113

2.6 Nomenclature and Sign Conventions ................................. 114

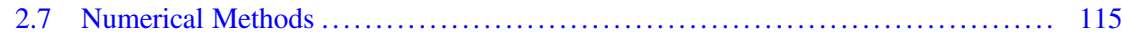

2.8 Choice of Independent Variables ..................................... 116

2.9 Geometrical Dimensions and Units of Physical Quantities .................. 117

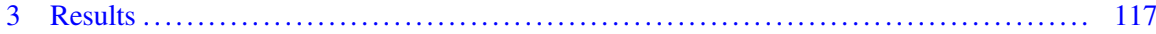

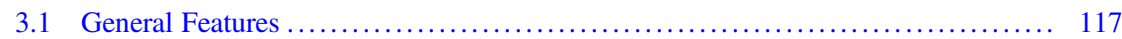

3.2 A Component of $\mathrm{Na}^{+}$Uptake Bypasses the Pump ......................... 119

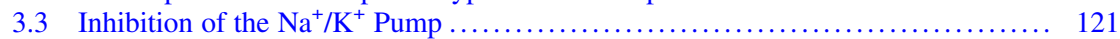

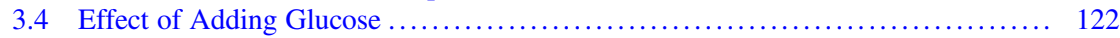

3.5 Blocking Water Channels of Apical Membrane ............................ 125

3.6 Volume Response of the Epithelium to a Luminal Osmotic Pulse ................ 129

3.7 Uphill Water Transport and Intraepithelial Water Fluxes .................... 130

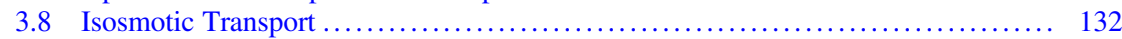

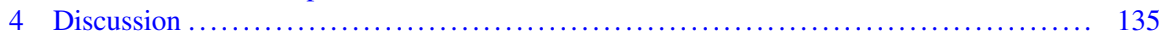

4.1 The Coupling Between Active Sodium Transport and Fluid Uptake ............ 135

4.2 Eliminating the Osmotic Permeability of Apical Membrane .................... 136

The original version of this chapter was revised. A correction to this chapter can be found at https://doi.org/10.1007/112_2020_40

E. H. Larsen $(\bowtie)$

Department of Biology, University of Copenhagen, Copenhagen, Denmark e-mail: ehlarsen@bio.ku.dk

J. N. Sørensen

Department of Wind Energy, Technical University of Denmark, Lyngby, Denmark e-mail: jnso@dtu.dk 
4.3 Transepithelial Osmotic Permeability Versus Osmotic Permeability of Individual Membranes ....................................................... 137

4.4 Truly Isosmotic Transport .......................................... 138

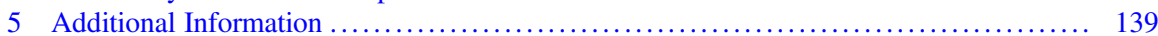

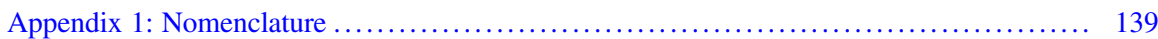

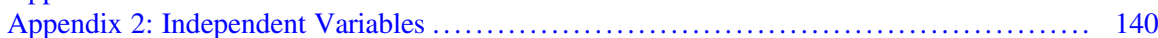

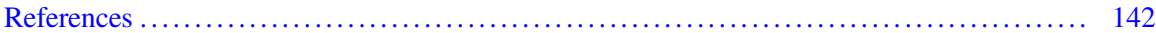

Abstract Our mathematical model of epithelial transport (Larsen et al. Acta Physiol. 195:171-186, 2009) is extended by equations for currents and conductance of apical SGLT2. With independent variables of the physiological parameter space, the model reproduces intracellular solute concentrations, ion and water fluxes, and electrophysiology of proximal convoluted tubule. The following were shown:

1. Water flux is given by active $\mathrm{Na}^{+}$flux into lateral spaces, while osmolarity of absorbed fluid depends on osmotic permeability of apical membranes.

2. Following aquaporin "knock-out," water uptake is not reduced but redirected to the paracellular pathway.

3. Reported decrease in epithelial water uptake in aquaporin-1 knock-out mouse is caused by downregulation of active $\mathrm{Na}^{+}$absorption.

4. Luminal glucose stimulates $\mathrm{Na}^{+}$uptake by instantaneous depolarization-induced pump activity ("cross-talk") and delayed stimulation because of slow rise in intracellular $\left[\mathrm{Na}^{+}\right]$.

5. Rate of fluid absorption and flux of active $\mathrm{K}^{+}$absorption would have to be attuned at epithelial cell level for the $\left[\mathrm{K}^{+}\right]$of the absorbate being in the physiological range of interstitial $\left[\mathrm{K}^{+}\right]$.

6. Following unilateral osmotic perturbation, time course of water fluxes between intraepithelial compartments provides physical explanation for the transepithelial osmotic permeability being orders of magnitude smaller than cell membranes' osmotic permeability.

7. Fluid absorption is always hyperosmotic to bath.

8. Deviation from isosmotic absorption is increased in presence of glucose contrasting experimental studies showing isosmotic transport being independent of glucose uptake.

9. For achieving isosmotic transport, the cost of $\mathrm{Na}^{+}$recirculation is predicted to be but a few percent of the energy consumption of $\mathrm{Na}^{+} / \mathrm{K}^{+}$pumps.

Keywords AQP-1 knock-out · Glucose absorption · Isosmotic transport · Kidney proximal tubule $\cdot$ Mathematical-modeling · Osmotic permeability $\cdot$ Time dependentand stationary states of water and ion fluxes

\section{Introduction}

In the study from A. K. Solomon's laboratory of Necturus proximal tubule in which net flux of $\mathrm{NaCl}$ and water were measured over the same period of time, reabsorbed fluid was isosmotic over a wide range of water fluxes. In the phrasing of the authors (Windhager et al. 1959), "water transport in the proximal tubule depends on the 
tubular $\mathrm{NaCl}$ concentration rather than upon the water activity," and "the driving force for water movement arises from the efflux of $\mathrm{NaCl}$ from tubule to plasma," which was shown to be inhibited by the $\mathrm{Na}^{+} / \mathrm{K}^{+}$-ATPase inhibitor ouabain (Schatzmann et al. 1958). Work from several groups confirmed isosmotic transport by kidney proximal tubule (Bennett et al. 1967; Kokko et al. 1971; Morel and Murayama 1970; Schafer et al. 1974) and by other low-resistance epithelia (Curran 1960; Diamond 1964). More recently, isosmotic transport was also observed in highresistance epithelia (Gaeggeler et al. 2011; Nielsen and Larsen 2007; Schafer 1993), indicating that the ability to transport water at osmotic equilibrium energized by the $\mathrm{Na}^{+} / \mathrm{K}^{+}$-ATPase is a general feature of transporting epithelia. This may occur even against an adverse osmotic gradient, confirming that epithelia are capable of spending metabolic energy to move water (Diamond 1964; Green et al. 1991; Nielsen and Larsen 2007; Parsons and Wingate 1958). The mechanism of isosmotic transport is debated (Andreoli and Schafer 1979; Fischbarg 2010; Larsen et al. 2009; Nedergaard et al. 1999; Spring 1999; Tripathi and Boulpaep 1989; Whittembury and Reuss 1992; Zeuthen 2000; Zeuthen et al. 2001). Since $\mathrm{Na}^{+} / \mathrm{K}^{+}$pumps are expressed in membranes lining the lateral intercellular space (DiBona and Mills 1979; Maunsbach and Boulpaep 1991; Mills et al. 1977; Padilla-Benavides et al. 2010; Stirling 1972) similarly to aquaporin water channels (Agre et al. 1993b), it is generally accepted that this space by way of osmosis couples the active $\mathrm{Na}^{+}$flux and the water flux and that isosmotic transport simply follows from a large water permeability (Altenberg and Reuss 2013).

Weinstein and Stephenson (1981) established tradition for applying mathematical formalisms in the analysis of steady state water and ion absorption by kidney proximal tubule (Weinstein 1986, 1992, 2013). Our steady state mathematical models of leaky epithelia (Larsen et al. 2000, 2002) have been expanded for computing time-dependent states (Larsen et al. 2009). The present analytical model comprising new apical glucose transport equations and comprehensive mathematical handling of electrical properties enables us to confront quantitatively computations with crucial experiments on kidney proximal tubule.

The present study has a dual purpose. Firstly, we present in detail complex relationships between active ion fluxes and water flows in an epithelium of extremely large membrane hydraulic permeabilities, as exemplified by mammalian proximal tubule of amplified apical and lateral plasma membrane areas (Welling and Welling 1975, 1988), which make this nephron segment one of the most waterpermeable epithelia in nature (Carpi-Medina et al. 1983; Schafer 1990). This is done by quantitative analysis of a mathematical model which comprises cellular and paracellular pathways for fluxes of ions, glucose, and water. It is an important quality of our treatment that water absorption is governed by a driving force resulting from solute fluxes and intraepithelial solute solvent coupling reflecting the conditions in vivo (Gottschalk 1963) and in microperfused isolated tubules (Green et al. 1991). By including glucose and electrical properties, commonly applied laboratory protocols can be simulated for investigating the explanatory power of the model over a wide range of observations. Besides analysis of relationships between volume flows and solute fluxes, our analysis comprises time-dependent states evoked by 
perturbation of, e.g., osmolarity of external solutions or "knock-out" of a specific membrane transporter providing novel insight into redistributions of water flows between cells and paracellular space.

The second purpose of the study is to analyse in the depth problems of importance for the function of vertebrate kidney that hitherto have been out of focus. Examples are the conflict between osmotic permeability of whole epithelium and that of individual membranes, with reference to the studies from Solomon's laboratory discussed above; the relative significance of sodium pump activity to aquaporin water channel osmotic permeability for the rate of water absorption; robustness of mathematical solutions giving isosmotic absorption; and the relative significance of transcellular and paracellular fluid absorption, respectively. Our analysis of every one of these problems provides novel information of definitive and general nature.

\section{Description of the Minimalistic Model}

\subsection{Functional Organization of Proximal Tubule Epithelium}

Mammalian proximal tubule is a heterocellular epithelium with three consecutive segments of individual functional and structural complexity (Maunsbach 1966; Welling and Welling 1988; Zhuo and Li 2013). All segments are engaged in isosmotic fluid absorption energized by lateral $\mathrm{Na}^{+} / \mathrm{K}^{+}$pumps. The minimalistic model epithelium reproduces $\mathrm{Na}^{+}$-coupled water transport in all three segments, and by having lumen-negative transepithelial potential difference and water absorption coupled predominantly to absorption of $\mathrm{NaCl}$ and glucose, the model epithelium has these features in common with the proximal convoluted tubule. It follows that the model discussed here does not handle acid-base transport and cannot, therefore, reproduce absorption of bicarbonate ions. However, by containing the essential module of subcellular complexity driving isosmotic transport, all conclusions of the present study apply to all three segments - and generally to other transporting epithelia.

The width of the lateral space (distance between neighbouring cells) is constant while neighbouring cells interdigitate in progressively more complicated way toward the cell base (Maunsbach 1973; Welling and Welling 1988). A quantitative stereologic study of size and shape of cells and lateral intercellular spaces (lis) of all three segments of proximal tubule indicated similar relatively large areas of apical membrane (comprising brush border surface and intervening membrane) and lateral membrane (Welling and Welling 1988). The area of serosal membrane contacting the basement membrane is much smaller than those of the above two membrane domains. The interspace basement membrane providing exit from the lateral intercellular space is about $10 \%$ of the area of the entire basement membrane. Morphometric analyses further indicated that the so-called basal infoldings do not stem from serosal membrane contacting the basement membrane but represent a 
complex lateral-membrane arrangement of arbitrary orientation in the basal $20 \%$ region of tubule cells (Welling et al. 1987a). A fluorometric micro-assay of $\mathrm{Na}^{+} / \mathrm{K}^{+}$ATPase (Garg et al. 1981) demonstrated highest expression of this enzyme in proximal convoluted tubule as compared to downstream segments of the nephron, and net $\mathrm{Na}^{+}$transport previously measured in microperfused tubule segments correlated well with their $\mathrm{Na}^{+} / \mathrm{K}^{+}$-ATPase activity. Immunocytochemical studies localized the $\mathrm{Na}^{+} / \mathrm{K}^{+}$-ATPase to lateral plasma membranes and to the abovementioned complex of lateral plasma membrane infoldings at the base of tubule cells (Kashgarian et al. 1985; Maunsbach and Boulpaep 1991). Immunochemical reaction was not observed on those areas of the basal plasma membrane directly contacting basal lamina (Kashgarian et al. 1985) nor is this transporter found on the luminal brush border (Jørgensen 1986). This agrees with studies on localization of $\left[{ }^{3} \mathrm{H}\right]$ ouabain in other transporting epithelia (DiBona and Mills 1979; Mills and DiBona 1977, 1978; Stirling 1972). In ileal intestinal mucosa, a thyroid epithelial FRT-cell line, and MDCK cells grown as a confluent monolayer on permeable filter support is the $\mathrm{Na}^{+} / \mathrm{K}^{+}$-ATPase present in lateral membranes of cells with no immunofluorescent staining neither at apical nor at serosal cell surfaces (Amerongen et al. 1989; Padilla-Benavides et al. 2010; Zurzolo and Rodriguezboulan 1993). Thus, in transporting epithelia, the lateral plasma membrane and the serosal plasma membrane constitute different functional domains implying that sodium ions transported into the cell through the apical plasma membrane are actively transported into lis for exiting the epithelium through the interspace basement membrane. Because the so-called "basolateral" osmotic permeability identified as AQP-1 (Agre et al. $1993 \mathrm{a}, \mathrm{b}$ ) is confined to the lateral membrane, the lateral intercellular space constitutes a compartment of its own with physically well-defined boundary toward the serosal (interstitial) compartment as depicted in Fig. 1a. Thus, for transepithelial osmotic equilibrium, water entering the epithelium through any membrane domain leaves the epithelium through the interspace basement membrane. This applies even if the serosal cell membrane's osmotic permeability is non-zero and follows from a slightly hyperosmotic cell water driving water into the cell not only from luminal solution but also from serosal bath. The above functional organization constitutes the prerequisite for truly isosmotic transport. Thus, quantitative analysis of water uptake by our minimalistic model provides insight into isosmotic transport by absorbing epithelia in general.

\subsection{Solute Flux Equations}

The computations presented in this paper do not depend on any particular assumption about the nature of luminal entrance mechanisms as long as we keep absolute ion fluxes and water flows in agreement with measured quantities. With this requirement being fulfilled, there are additional features of the minimalistic model 
a

b

Outside (luminal) compartment

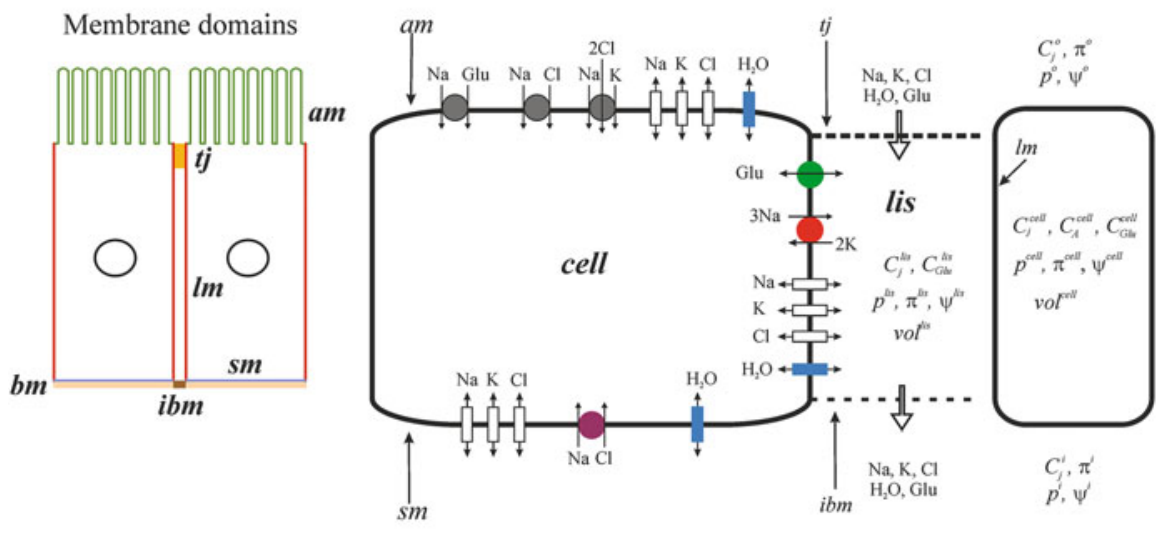

Inside (serosal) compartment

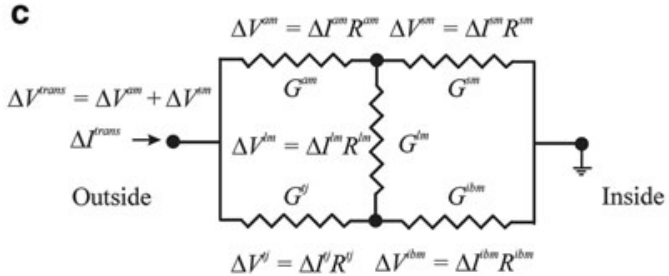

Fig. 1 (a) Cell membranes of transporting epithelia constitute three functionally different domains. Localization of fluorescence probes or radioactive ${ }^{3} \mathrm{H}$-labeling of antibodies raised against transport proteins indicated that lateral and serosal membranes constitute functionally different domains; see text for references. As a consequence, the notion "basolateral membrane" would have to be avoided. am apical membrane with microvilli, $t j$ tight junction, $I m$ lateral membrane, $s m$ serosal membrane, $\mathrm{bm}$ basement membrane in light brown color that includes the interspace basement membrane, $\mathrm{ibm}$ indicated by darker brown color. (b) Transport systems of the minimalistic epithelial model with definitions and nomenclature. Transport systems and symbols as defined in text and Appendix 1 and 2. In the investigation of conditions for obtaining truly isosmotic transport is the $1 \mathrm{Na}^{+}: 1 \mathrm{Cl}$ cotransporter activated for obtaining an overall isosmotic transport (see text for further explanation). (c) The five membranes of the epithelium constitute a bridge circuit. The solution to the mathematical problem for a given set of independent variables contains values of the five membrane resistors indicated above. The resistance of the bridge circuit, however, cannot be calculated according to rules for series and parallel resistors. Therefore, it is computed by simulating a current injection, $\Delta I^{\text {trans }}$, and applying Kirchhoff's rules for solving the set of five current equations by the "solve routine" of Mathematica $\odot$. Subsequently, the five membrane currents, $\Delta I^{m}$, are used for calculating change in membrane potentials, transepithelial resistance $\left(R^{\text {trans }}=\Delta V^{\text {trans }} / \Delta I^{\text {trans }}\right)$, and fractional resistance of the apical membrane. The resistance notation in Mathematica $\odot$ equations are defined as follows: $R^{a m}=R_{1}, R^{s m}=R_{2}, R^{l m}=R_{3}, R^{t j}=R_{4}$, and $R^{i b m}=R_{5}$. See methods for details

that would have to be met for our purpose. In the absence of glucose and amino acids, Frömter's seminal study reported a fairly large apical membrane conductance of about $4 \mathrm{mS} \mathrm{cm}^{-2}$ with a ratio of the resistance of the luminal membrane to the transcellular resistance of 0.8 (Frömter 1982). In the cell, both $\mathrm{K}^{+}$and $\mathrm{Cl}^{-}$are above 
thermodynamic equilibrium (Cassola et al. 1983; Edelman et al. 1978; Windhager 1979). Since neither is secreted into the luminal solution, the above electrical conductance is governed predominantly by a $\mathrm{Na}^{+}$conductance. $\mathrm{A} \mathrm{Na}^{+}$conductance is associated with the $3 \mathrm{Na}^{+}: 1 \mathrm{HPO}_{4}{ }^{2-}$ cotransporter. Frömter (1982) perfused the kidney tubule with physiological saline containing $1 \mathrm{mM} \mathrm{HPO}_{4}{ }^{2-}$; thus with a coupling ratio of $3 \mathrm{Na}^{+}: 1 \mathrm{HPO}_{4}{ }^{2-}$, it is unlikely that this transporter accounts for the relatively very large conductance of $4 \mathrm{mS} / \mathrm{cm}^{2}$, which leaves a $\mathrm{Na}^{+}$channel as the most likely candidate for the $\mathrm{Na}^{+}$conductance of the apical membrane. This goes along with the study by Morel and Murayama (1970), who obtained isosmotic reabsorption in microperfused rat proximal tubule in the absence of phosphate ions in the luminal perfusion solution. Added to this, a sodium ion channel was disclosed by patch clamp of rabbit proximal straight tubule (Gögelein and Greger 1986). The Goldman-Hodgkin-Katz (GHK) constant field equations are applied for handling this as well as electrodiffusion fluxes in the other ion channels including tight junction and interspace basement membrane (Goldman 1943; Hodgkin and Katz 1949; Sten-Knudsen 2002):

$$
J_{j}=\left(\frac{z_{j} F V}{R T} P_{j}\right) \frac{C_{j}^{(I)} \exp \left[z_{j} F V /(R T)\right]-C_{j}^{(I I)}}{\exp \left[z_{j} F V /(R T)\right]-1}
$$

The associated chord conductance is:

$$
G_{j}=\left(\frac{\left(z_{j} F\right)^{2} V}{R T} P_{j}\right) \frac{C_{j}^{(I)} \exp \left[z_{j} F V /(R T)\right]-C_{j}^{(I I)}}{\left(\exp \left[z_{j} F V /(R T)\right]-1\right)\left(V-V_{j}^{e q}\right)}
$$

$P_{j}$ is the ion permeability and $V$ potential difference across the membrane. $\mathrm{I}=$ lumen and II = cell for the apical membrane, $\mathrm{I}=$ cell and $\mathrm{II}=$ lis for the lateral membrane, and $\mathrm{I}=$ cell and $\mathrm{II}=$ seros $a$ for the serosal membrane. The proximal tubule reabsorbs 50-70\% of the filtered $\mathrm{K}^{+}$load. Wilson et al. (1997) showed that cyanide caused a reduction in net potassium flux over the entire range of fluid fluxes in their doubleperfusion experiments. Subsequent single-perfusion experiments (tubule lumen only) using the specific $\mathrm{K}^{+}-\mathrm{H}^{+}$-ATPase inhibitor, $\mathrm{SCH} 28080$, did not reveal evidence for primary active $\mathrm{K}^{+}$absorption. The authors discussed the possibility that tubular absorption of $\mathrm{K}^{+}$is accomplished by paracellular solvent drag. This mechanism is included in our model and will be quantitatively evaluated in Results for concluding that solvent drag cannot account for transtubular absorption of $\mathrm{K}^{+}$. The principal importance of active $\mathrm{K}^{+}$absorption is independent of the molecular design of the transporter. It is of importance, however, that the transepithelial active flux of potassium ions results in a $\mathrm{K}^{+}$concentration of the absorbate that is close to the concentration of $\mathrm{K}^{+}$in serosal fluid. The $\mathrm{K}^{+}$absorption against the prevailing small transepithelial electrochemical potential difference shall be accounted for by assuming $\left(1 \mathrm{Na}^{+}, 1 \mathrm{~K}^{+}, 2 \mathrm{Cl}^{-}\right)$cotransport across the apical membrane: 


$$
J_{j}^{N a K 2 C l, m}=r \cdot K^{N a K 2 C l, m}\left[C_{N a}^{(I)} \cdot C_{K}^{(I)} \cdot\left(C_{C l}^{(I)}\right)^{2}-C_{N a}^{(I I)} \cdot C_{K}^{(I I)} \cdot\left(C_{C l}^{(I I)}\right)^{2}\right]
$$

Here, $r=1$ for $\mathrm{Na}^{+}$and $\mathrm{K}^{+}$and $r=2$ for $\mathrm{Cl}^{-}$. In agreement with cellular $\mathrm{Cl}^{-}$ accumulation via a $\mathrm{Na}^{+}$-dependent cotransporter in Necturus (Spring and Kimura 1978, 1979) and rat (Karniski and Aronson 1987; Warnock and Lucci 1979), we assume that a $\left(1 \mathrm{Na}^{+}, 1 \mathrm{Cl}^{-}\right)$cotransporter is present in the apical membrane:

$$
J_{j}^{N a C l, m}=K^{N a C l, m}\left[C_{N a}^{(I)} \cdot\left(C_{C l}^{(I)}\right)-C_{N a}^{(I I)} \cdot\left(C_{C l}^{(I I)}\right)\right]
$$

For generalizing the description, apical $\mathrm{Cl}^{-}$and $\mathrm{K}^{+}$channels are included, but in the present calculations, they do not carry significant fluxes because they are largely quiescent under normal conditions (Boron and Boulpaep 2017).

In 1976, a sodium ion/proton antiporter was discovered in vesicles isolated from renal brush-border membranes of rat by Murer et al. (1976); it was cloned and named NHE3 (Sardet et al. 1989). As recently reviewed by Zhuo and Li (2013), subsequent studies confirmed its function as pathway for eliminating protons in exchange for luminal sodium ions in kidney proximal nephron. The NHE3 antiporter operates in series with a lateral electrogenic cotransporter of stoichiometry $1 \mathrm{Na}^{+}: 3 \mathrm{HCO}_{3}{ }^{-}$. Bicarbonate is regenerated from $\mathrm{OH}^{--}$and $\mathrm{CO}_{2}$ catalyzed by a cytoplasmic carbonic anhydrase (Boron and Boulpaep 2017). The operation of this enzyme together with the NHE3 antiporter is assumed to recover quantitatively $\mathrm{HCO}_{3}{ }^{-}$, which is transported together with sodium ions into the interstitial fluid (Boron and Boulpaep 1983a, b; Yoshitomi et al. 1985). At this stage of our studies, we aim at transport features that are independent of acid-base transporters. As shall be demonstrated below, this "minimalistic" model is excellently suited for analysis of general features of isosmotic transport, e.g., none of our conclusions are being affected by this simplification.

Driving forces for glucose uptake across the luminal membrane of rat convoluted proximal tubule are the transmembrane $\mathrm{Na}^{+}$concentration gradient, the transmembrane glucose concentration gradient, and the membrane potential. The transporter saturates with luminal $\mathrm{Na}^{+}$concentration as well as with luminal glucose concentration (Samarzija et al. 1982). Glucose is coupled to $\mathrm{Na}^{+}$uptake by the $\mathrm{Na}^{+} / \mathrm{D}-$ glucose cotransporter-2 (SGLT2) with a stoichiometry of $1 \mathrm{Na}^{+}: 1$ glucose in tubule segments $\mathrm{S} 1$ and $\mathrm{S} 2$ and $\mathrm{Na}^{+} / \mathrm{D}$-glucose cotransporter-1 (SGLT1) with a stoichiometry of $2 \mathrm{Na}^{+}: 1$ glucose in tubule segments S3 (Ghezzi et al. 2018; Hummel et al. 2011; Parent et al. 1992; Turner and Moran 1982; Turner and Silverman 1977). SGLT2 is rheogenic, and with $150 \mathrm{mM}$ external $\mathrm{Na}^{+}$concentration, the transporter generates a nonlinear current-voltage relationship reflecting voltage dependence of the $\mathrm{Na}^{+}$current (Hummel et al. 2011; Parent et al. 1992). With sign conventions in epithelial studies, inward $\mathrm{Na}^{+}$currents are positive and $V^{a m}=\psi^{o}-\psi^{\text {cell }}$ with the associated current-voltage relationship being upward concave. This corresponds to the downward concave current-voltage relationship obtained with SGLT2 expressed in Xenopus oocyte (Parent et al. 1992) or HEK293T cells (Hummel et al. 2011) where inward $\mathrm{Na}^{+}$currents are given a negative sign, and membrane potential is defined as $V=\psi^{\text {cell }}-\psi^{o}$. The last mentioned studies reported zero 
SGLT2-current in the absence of external glucose or in the absence of external $\mathrm{Na}^{+}$. Thus, in the absence of luminal glucose, the $\mathrm{Na}^{+}$conductance of SGLT2 is zero. Finally, the reversal potential of the SGLT2-cotransporter $E_{r e v}^{a m}, \mathrm{Glu} \cdot \mathrm{Na}$ would have to fulfill the requirement that Gibbs free energy remains constant following one transport cycle as expressed by (Schultz 1980):

$$
E_{\text {rev }}^{a m, G l u \cdot N a}=\frac{R T}{F} \ln \frac{C_{G l u}^{o} \cdot C_{N a}^{o}}{C_{G l u}^{c e l l} \cdot C_{N a}^{c e l l}}
$$

The abovementioned requirements are fulfilled by the following set of equations:

$$
\begin{gathered}
J_{N a}^{a m, G l u \cdot N a}=\left(\frac{P^{G l u \cdot N a} F V^{a m}}{R T}\right)\left(\frac{C_{G l u}^{o}}{K_{G l u}^{G l u} \cdot N a}+C_{G l u}^{o}\right)\left(\frac{C_{N a}^{o}}{K_{N a}^{G l u \cdot N a}+C_{N a}^{o}}\right) \\
\times \frac{C_{G l u}^{o} C_{N a}^{o} \exp \left\{F V^{a m} /(R T)\right\}-C_{G l u}^{c e l l} C_{N a}^{c e l l}}{\exp \left\{F V^{a m} /(R T)\right\}-1} \\
J_{G l u}^{a m, G l u \cdot N a}=J_{N a}^{a m, G l u \cdot N a} \\
V^{a m}=\psi^{o}-\psi^{\text {cell }}
\end{gathered}
$$

$P^{G l u \cdot \mathrm{Na}^{+}}$is the maximal turnover of SGLT2, where $K_{\mathrm{Glu}}^{\mathrm{Glu} \cdot \mathrm{Na}^{+}} \approx 5 \mathrm{mM}$ and $\mathrm{K}_{\mathrm{Na}^{+}}^{\mathrm{Glu} \cdot \mathrm{Na}^{+}}$ $\approx 25 \mathrm{mM}$ are apparent dissociation constants of the transporter's binding sites (Hummel et al. 2011). For obtaining the associated chord (integral) conductance, the current carried by SGLT2 is introduced and multiplied by unity expressed as $\left(V^{a m}-E_{\text {rev }}^{a m, G l u}\right) /\left(V^{a m}-E_{\text {rev }}^{a m, G l u}\right)$ :

$$
I_{N a}^{a m, G l u \cdot N a}=\frac{P^{\prime} F^{2} V^{a m}\left[C_{G l u}^{o} C_{N a}^{o} \exp \left\{F V^{a m} /(R T)\right\}-C_{G l u}^{c e l l} C_{N a}^{c e l l}\right]}{R T\left[\exp \left\{F V^{a m} /(R T)\right\}-1\right]\left(V^{a m}-E_{\text {rev }}^{a m, G l u}\right)}\left(V^{a m}-E_{\text {rev }}^{a m, G l u}\right)
$$

By having the form $I_{j}=G_{j}\left(V_{m}-E_{j}\right)$, the integral conductance is calculated from:

$$
G_{N a}^{a m, G l u \cdot N a}=\frac{P^{\prime} F^{2} V^{a m}\left[C_{G l u}^{o} C_{N a}^{o}-C_{G l u}^{c e l l} C_{N a}^{c e l l} \exp \left\{F V^{a m} /(R T)\right\}\right]}{R T\left[\exp \left\{F V^{a m} /(R T)\right\}-1\right]\left(V^{a m}-E_{\text {rev }}^{a m, G l u}\right)}
$$

where $E_{r e v}^{a m}, \mathrm{Glu} \cdot \mathrm{Na}$ is given by Eq. (3b) and $P^{\prime}$ by:

$$
P^{\prime}=P^{G l u \cdot N a}\left(\frac{C_{G l u}^{o}}{K_{G l u}^{G l u \cdot N a}+C_{G l u}^{o}}\right)\left(\frac{C_{N a}^{o}}{K_{N a^{+}}^{G l u \cdot N a}+C_{N a}^{o}}\right)
$$

Other SGLT2-models also handle saturation kinetics and substrate interactions, e.g., Layton et al. (2015) and Weinstein (1985). Unlike these previous treatments, Eqs. (3a-3d) cover the transporter's contributions to membrane potential and 
membrane conductance; in the present study, this is required for its validation by comparing computations with experiments.

Immuno-labeling has shown that $\mathrm{Na}^{+} / \mathrm{K}^{+}$-ATPase (Skou 1965) is expressed exclusively in lateral plasma membrane (Kashgarian et al. 1985). The active cation fluxes are saturating function of cell $\mathrm{Na}^{+}\left(C_{N a}^{\text {cell }}\right)$ and concentration of $\mathrm{K}^{+}$in lateral intercellular space $\left(C_{K}^{\text {lis }}\right)$ (Garay and Garrahan 1973; Goldin 1977; Jørgensen 1980). The pump rate is also a function of the electrical work done in moving one charge across the membrane per pump cycle (Thomas 1972), which is a function of lateral membrane potential, $V^{I m}$, and the electrical work contributed by the pump-ATPase, here denoted $E^{\text {pump }}$. The above properties are fulfilled by the following set of equations (Larsen et al. 2009):

$$
\begin{aligned}
& J_{N a}^{l m, \text { pump }}=\frac{P_{N a, K}^{l m, \text { pump }}}{F}\left(\frac{C_{N a}^{\text {cell }}}{K_{N a}^{l m, \text { pump }}+C_{N a}^{\text {cell }}}\right)^{3}\left(\frac{C_{K}^{l i s}}{K_{K}^{l m, \text { pump }}+C_{K}^{l i s}}\right)^{2}\left[V^{l m}+E^{\text {pump }}\right] \\
& J_{K}^{l m, \text { pump }}=-\frac{2}{3} J_{N a}^{l m, \text { pump }} \\
& V^{l m}=\psi^{\text {cell }}-\psi^{l i s}
\end{aligned}
$$

$\frac{P_{N a, K}^{l m, p u m p}}{F}$ of dimension of mol s${ }^{-1} \mathrm{~V}^{-1}$ per unit area of plasma membrane represents the $\mathrm{Na}^{+}$efflux through the sodium pump saturated with internal $\mathrm{Na}^{+}$and external $\mathrm{K}^{+}$at normal cytoplasmic ATP levels. With a $3 \mathrm{Na}^{+}: 2 \mathrm{~K}^{+}$stoichiometry, the expression for the pump current is:

$$
I^{\text {lm,pump }}=\frac{P_{N a, K}^{\text {lm, pump }}}{3}\left(\frac{C_{N a}^{\text {cell }}}{K_{N a}^{l m, \text { pump }}+C_{N a}^{\text {cell }}}\right)^{3}\left(\frac{C_{K}^{\text {lis }}}{K_{K}^{\text {lm,pump }}+C_{K}^{\text {lis }}}\right)^{2}\left[V^{l m}+E^{\text {pump }}\right]
$$

Eq. (4b) gives pump currents that are linearly dependent on membrane potential, which is an acceptable approximation for the interval, $-110 \mathrm{mV}<V^{l m}<-5 \mathrm{mV}$ (Gadsby and Nakao 1989; Läuger 1991; Wu and Civan 1991) that covers computations of the present study. The reversal potential of pump currents is $E_{r e v}^{\text {pump }}=-E^{\text {pump }}$ with free energy of ATP hydrolysis, $\Delta G_{A T P} \approx-60 \mathrm{~kJ} / \mathrm{mol}$ and stoichiometry of $3 \mathrm{Na}^{+}: 2 \mathrm{~K}^{+}: 1$ ATP, $E^{\text {pump }}$ is about $200 \mathrm{mV}$ which is within the range discussed by de Weer et al. (1988) and used in all our computations independently of the rate of pump flux. Unlike the reversal potential of the $\mathrm{Na}^{+}$pump of a tight epithelium, e.g., frog skin (Larsen 1973; Eskesen and Ussing 1985), the last mentioned assumption is plausible for proximal tubule cells of high density of mitochondria in remarkably close contact with pump sites that would minimize the diffusion distance between sites of dephosphorylation of ATP and rephosphorylation of ADP, respectively (Dørup and Maunsbach 1997). Following Läuger (1991), by inspection of Eq. (4b) in the range indicated where $P_{N a, K}^{l m, \text { pump }}$ is considered constant, the integral conductance of the pump would be: 


$$
G^{l m, \text { pump }}=\frac{P_{N a, K}^{l m, \text { pump }}}{3}\left(\frac{C_{N a}^{c e l l}}{K_{N a}^{l m, p u m p}+C_{N a}^{c e l l}}\right)^{3}\left(\frac{C_{K}^{l i s}}{K_{K}^{l m, p u m p}+C_{K}^{l i s}}\right)^{2}
$$

Early mathematical models of proximal tubule by Sackin and Boulpaep (1975) and Weinstein $(1986,1992)$ did not include membrane potential as driving force for pump currents. Other studies included the membrane conductance-dependent electrogenic contribution of the pump to membrane potential (Lew et al. 1979 and Larsen 1991). The above Eq. (4a) is an expansion of previous treatments by acknowledging that potential per se is driving force for pump currents. The advantage of this new treatment shall be underscored in Results.

The expression for convection-diffusion of glucose across tight junction and interspace basement membrane obeys the Smoluchowski equation (Smoluchowski 1915). It was derived by Hertz (1922), and when applied to a membrane of reflection coefficient indicated by $\sigma$, the expression reads (Larsen et al. 2000):

$$
J_{G l u}=J_{V}\left(1-\sigma_{G l u}\right) \frac{C_{G l u}^{(I)} \exp \left[J_{V}\left(1-\sigma_{G l u}\right) / P_{G l u}\right]-C_{G l u}^{(I I)}}{\exp \left[J_{V}\left(1-\sigma_{G l u}\right) / P_{G l u}\right]-1}
$$

The equation was expanded for covering the convection-electrodiffusion regime (Larsen et al. 2002),

$$
J_{j}=\left(\frac{z_{j} F V}{R T} P_{j}+J_{V}\left(1-\sigma_{j}\right)\right) \frac{C_{j}^{(I)} \exp \left[z_{j} F V /(R T)\right] \exp \left[J_{V}\left(1-\sigma_{j}\right) / P_{j}\right]-C_{j}^{(I I)}}{\exp \left[z_{j} F V /(R T)\right] \exp \left[J_{V}\left(1-\sigma_{j}\right) / P_{j}\right]-1}
$$

Here, it is assumed that the pore is symmetrical such that reflection coefficient and partition coefficient $(\beta)$ are related by $\sigma=(1-\beta)$ as shown by Finkelstein (1987). $J_{V}$ is the volume flux from compartment I (lumen or lis) to II (lis or serosa), and $\sigma_{j}$ is the reflection coefficient of ion $j$ of the membrane. Exit of glucose across lateral membrane is governed by saturation kinetics of a symmetrical carrier (Stein 1967),

$$
J_{G l u}^{l m}=J_{G l u}^{l m, \max } \frac{K_{G l u}^{l m}\left(C_{G l u}^{c}-C_{G l u}^{l i s}\right)}{\left(K_{G l u}^{l m}+C_{G l u}^{c}\right)\left(K_{G l u}^{l m}+C_{G l u}^{l i s}\right)}
$$

\subsection{Water Flux Equations}

In agreement with cloned aquaporins of proximal tubule (Borgnia et al. 1999), we assume reflection coefficient of unity for water flow through all plasma membranes. Thus, equations for the respective volume fluxes per unit area of apical plasma membrane are, 


$$
\begin{aligned}
J_{V}^{\text {am }}= & L_{p}^{\text {am }}\left\{R T\left(C_{N a}^{\text {cell }}+C_{K}^{\text {cell }}+C_{C l}^{\text {cell }}+C_{A}^{\text {cell }}+C_{G l u}^{\text {cell }}-C_{N a}^{\text {lumen }}-C_{K}^{\text {lumen }}-C_{C l}^{\text {lumen }}-C_{G l u}^{\text {lumen }}\right)\right. \\
& \left.+\left(p^{\text {lumen }}-p^{\text {cell }}\right)\right\} \\
J_{V}^{l m}= & L_{p}^{l m}\left\{R T\left(C_{N a}^{\text {lis }}+C_{K}^{\text {lis }}+C_{C l}^{\text {lis }}+C_{G l u}^{\text {lis }}-C_{N a}^{\text {cell }}-C_{K}^{\text {cell }}-C_{C l}^{\text {cell }}-C_{A}^{\text {cell }}-C_{G l u}^{\text {cell }}\right)\right. \\
& \left.+\left(p^{\text {cell }}-p^{\text {lis }}\right)\right\} \\
J_{V}^{\text {sm }}= & L_{p}^{\text {sm }}\left\{R T\left(C_{N a}^{\text {serosa }}+C_{K}^{\text {serosa }}+C_{C l}^{\text {serosa }}+C_{G l u}^{\text {serosa }}-C_{N a}^{\text {cell }}-C_{K}^{\text {cell }}-C_{C l}^{\text {cell }}-C_{A}^{\text {cell }}-C_{G l u}^{\text {cell }}\right)\right. \\
& \left.+\left(p^{\text {cell }}-p^{\text {serosa }}\right)\right\}
\end{aligned}
$$

Water fluxes through membranes delimiting the lateral intercellular space from external solutions have to include reflection coefficients,

$$
\begin{aligned}
J_{V}^{t j}= & L_{p}^{t j}\left\{R T \left[\sigma_{N a}^{t j}\left(C_{N a}^{\text {lis }}-C_{N a}^{\text {lumen }}\right)+\sigma_{K}^{t j}\left(C_{K}^{\text {lis }}-C_{K}^{\text {lumen }}\right)\right.\right. \\
& \left.\left.+\sigma_{C l}^{t j}\left(C_{C l}^{\text {lis }}-C_{C l}^{\text {lumen }}\right)+\sigma_{G l u}^{t j}\left(C_{G l u}^{\text {lis }}+C_{G l u}^{\text {lumen }}\right)\right]+\left(p^{\text {lumen }}-p^{\text {lis }}\right)\right\} \\
J_{V}^{i b m}= & L_{p}^{i b m}\left\{R T \left[\sigma_{N a}^{i b m}\left(C_{N a}^{\text {serosa }}-C_{N a}^{\text {lis }}\right)+\sigma_{K}^{i b m}\left(C_{K}^{\text {serosa }}-C_{K}^{\text {lis }}\right)\right.\right. \\
& \left.\left.+\sigma_{C l}^{i b m}\left(C_{C l}^{\text {serosa }}-C_{C l}^{\text {lis }}\right)+\sigma_{G l u}^{i b m}\left(C_{G l u}^{\text {serosa }}+C_{G l u}^{\text {lis }}\right)\right]+\left(p^{\text {lis }}-p^{\text {serosa }}\right)\right\}
\end{aligned}
$$

Rather than hydraulic conductance, $L_{p}$, in the text, we refer to osmotic permeability, $P_{f}$. With molar volume of water indicated by $\bar{V}_{W}, L_{p}$ and $P_{f}$ are related by Finkelstein (1987),

$$
P_{f}=\frac{R T L_{p}}{\bar{V}_{W}}
$$

Mean valence of nondiffusible anions in the cell with concentration, $C_{A}^{\text {cell }}$, is denoted by $z_{A}$. Thus, the two electroneutrality conditions are given by:

$$
\begin{gathered}
C_{A}^{c e l l}=- \\
\left.C_{C l}^{l i s}=C_{N a}^{\text {cell }}+C_{K}^{\text {cell }}-C_{C l}^{c e l l}\right) / z_{A} \\
\end{gathered}
$$

If $I^{\text {clamp }}$ is the transepithelial clamping current and $I_{j}$ is the current carried by $j$ through the membrane indicated by superscript $\left(j=\mathrm{Na}^{+}, \mathrm{K}^{+}\right.$, or $\left.\mathrm{Cl}^{-}\right)$, the mathematical solution would have to obey the requirement:

$$
I^{\text {clamp }}=I_{N a}^{a m}+I_{N a}^{t j}+I_{K}^{a m}+I_{K}^{t j}+I_{C l}^{a m}+I_{C l}^{t j}
$$

where $I^{\text {clamp }}=0$ ("open circuit") defines the mathematical solution containing the transepithelial potential difference. 


\subsection{Compliant Model and Volumes of Intraepithelial Compartments}

For obtaining the hydrostatic pressure of the cell, we followed Weinstein and Stephenson $(1979,1981)$ and introduce a compliance model that assumes linear relationship between cell volume and cell pressure. If it is further assumed that the hydrostatic pressure of the cell adjusts itself to a value between ambient pressures weighted relative to the local compliant constants that are given the symbol $\mu^{m}$, we can write (Larsen et al. 2000),

$$
p^{\text {cell }}=\frac{\mu^{a m}}{\mu^{a m}+\mu^{l m}+\mu^{s m}} p^{l \text { lumen }}+\frac{\mu^{l m}}{\mu^{a m}+\mu^{l m}+\mu^{s m}} p^{l i s}+\frac{\mu^{s m}}{\mu^{a m}+\mu^{l m}+\mu^{s m}} p^{\text {serosa }}
$$

Introducing relative compliance constants,

$$
p^{\text {cell }}=\bar{\mu}^{a m} p^{l u m e n}+\bar{\mu}^{l m} p^{l i s}+\bar{\mu}^{\text {sm }} p^{\text {serosa }}
$$

With the volume of lis in the absence of fluid transport denoted, Vol $^{l i s, r e f}$, we have (Larsen et al. 2002):

$$
V o l^{l i s}=\operatorname{Vol}^{l i s, r e f}\left[1+\mu^{l m}\left(p^{l i s}-p^{c e l l}\right)\right]
$$

$D^{\text {cell }}$ and $M_{A}$ are number of cells per unit area of apical membrane and amount of nondiffusible anions per cell, respectively. Hence, cell volume is:

$$
\text { Vol }^{\text {cell }}=D^{\text {cell }} M_{A} / C_{A}^{\text {cell }}
$$

Here, $C_{A}^{\text {cell }}$ belongs to dependent variables.

\subsection{Electrical-Circuit Analysis}

Shown in Fig. 1c, the five epithelial membranes constitute a bridge circuit. For convenience, in the Mathematica $\subset$ equations below, the five membranes are indicated by $a m=1, s m=2, l m=3, t j=4$, and $i b m=5$. The method used for calculating the transepithelial conductance (resistance) is as follows. Having chosen values for independent variables, the numerical solution provides all primary dependent variables. Integral conductances calculated as specified above are used to calculate the resistance of each of the five membranes, $R_{1} \ldots R_{5}$. Simulating a step change of the current $\Delta I^{\text {trans }}$ through the circuit, Kirchhoff's rules are applied for setting up five simultaneous linear equations, 


$$
\begin{aligned}
& I_{1} R_{1}+I_{3} R_{3}-I_{4} R_{4}=0 \\
& I_{3} R_{3}+I_{5} R_{5}-I_{2} R_{2}=0 \\
& I_{2}+I_{5}-\Delta I^{\text {trans }}=0 \\
& I_{1}-I_{2}-I_{3}=0 \\
& I_{4}-I_{3}-I_{5}=0
\end{aligned}
$$

The currents flowing through the five resistors were obtained by using the solve routine of Mathematica $\mathrm{C}$ :

$$
\begin{gathered}
I_{1}=-\frac{-\left(R_{2} R_{4}+R_{3} R_{4}+R_{3} R_{5}+R_{4} R_{5}\right)}{R_{1} R_{2}+R_{1} R_{3}+R_{2} R_{3}+R_{2} R_{4}+R_{3} R_{4}+R_{1} R_{5}+R_{3} R_{5}+R_{4} R_{5}} \Delta I^{\text {trans }} \\
I_{2}=\Delta I^{\text {trans }}+\frac{\left(R_{1} R_{3}+R_{2}\left(R_{1}+R_{3}+R_{4}\right)\right)}{-R_{1} R_{3}-R_{1} R_{4}-R_{2}\left(R_{1}+R_{3}+R_{4}\right)-R_{5}\left(R_{1}+R_{3}+R_{4}\right)} \Delta I^{\text {trans }} \\
I_{3}=-\frac{\left(R_{2} R_{4}+R_{1} R_{5}\right)}{R_{1} R_{2}+R_{1} R_{3}+R_{2} R_{3}+R_{2} R_{4}+R_{3} R_{4}+R_{1} R_{5}+R_{3} R_{5}+R_{4} R_{5}} \Delta I^{\text {trans }} \\
I_{4}=-\frac{-\left(R_{1} R_{2}-R_{1} R_{3}-R_{2} R_{3}-R_{1} R_{5}\right)}{R_{1} R_{2}+R_{1} R_{3}+R_{2} R_{3}+R_{2} R_{4}+R_{3} R_{4}+R_{1} R_{5}+R_{3} R_{5}} \Delta I^{\text {trans }} \\
I_{5}=-\frac{\left(R_{1} R_{3}+R_{2}\left(R_{1}+R_{3}+R_{4}\right)\right)}{-R_{1} R_{3}-R_{3} R_{4}-R_{2}\left(R_{1}+R_{3}+R_{4}\right)-R_{5}\left(R_{1}+R_{3}+R_{4}\right)} \Delta I^{\text {trans }}
\end{gathered}
$$

The transepithelial electrical potential displacement $\Delta V^{\text {trans }}$ and the resistance of the apical (luminal) membrane relative to the transcellular resistance are given by the relations,

$$
\begin{aligned}
& \Delta V^{\text {trans }}=I_{1} R_{1}+I_{2} R_{2} \\
& F R^{\text {apical }}=I_{1} R_{1} / \Delta V^{\text {trans }}
\end{aligned}
$$

Finally, the transepithelial conductance is calculated as $G_{t}=\Delta I^{\text {trans }} / \Delta V^{\text {trans }}$.

\subsection{Nomenclature and Sign Conventions}

Nomenclature is indicated in Fig. 1b and Appendix 1. The model comprises four well-stirred compartments: outside (luminal-) compartment $(o)$, cell compartment (cell), lateral intercellular space (lis), and inside (serosal-, interstitial-) compartment (i). These are confined by five membranes: apical ( $\mathrm{am})$, serosal $(\mathrm{sm})$, lateral $(\mathrm{lm})$, tight junction $(\mathrm{tj})$, and intercellular basement membrane $(\mathrm{ibm})$. The primary 
unknowns include cellular and paracellular concentrations of $\mathrm{Na}^{+}, \mathrm{K}^{+}$, and $\mathrm{Cl}^{-}$, glucose and nondiffusible intracellular anions, hydrostatic pressures in cell and lis, and electrical potentials in cell, lis, and outside compartment. Fluxes directed from lumen to cell and lis, from cell to serosa and lis, and from lis to serosa are positive. Electrical potentials are indicated with reference to serosal compartment $\left(\psi^{i} \equiv 0\right)$ so that the individual membrane potentials are given by $V^{s m}=\psi^{\text {cell }}-\psi^{i}$, $V^{l m}=\psi^{\text {cell }}-\psi^{l i s}, V^{a m}=\psi^{o}-\psi^{\text {cell }}, V^{t j}=\psi^{o}-\psi^{l i s}$, and $V^{i b m}=\psi^{l i s}-\psi^{i}$.

\subsection{Numerical Methods}

The set of equations can be solved for both steady states and time-dependent states. In the general case, the transport equations for water and solutes are written as (Larsen et al. 2009):

$$
\begin{gathered}
\frac{d \bar{V}}{d t}=\sum_{m} J_{\bar{V}} \\
\frac{d\left(\bar{V} \cdot C_{S}\right)}{d t}=\sum_{m} J_{S}
\end{gathered}
$$

where $\bar{V}$ denotes the volume of cell or lateral intercellular space, and $J_{\bar{V}}$ and $J_{S}$ denote water and solute fluxes, respectively, through the various membranes, with $m$ indicating membrane $(m=1-5)$. In steady state, left hand side is zero. When transients are studied, time-dependent behavior of Eqs. (20) and (21) needs to be simulated. To solve the equations in time, we utilize second-order accurate, threepoint backward difference schemes (Taylor expansion) as follows:

$$
\begin{gathered}
\frac{1}{2 \Delta t}\left[3 \bar{V}^{(n)}-4 \bar{V}^{(n-1)}+\bar{V}^{(n-2)}\right]=\sum_{j} J_{\bar{V}}^{(n)} \\
\frac{1}{2 \Delta t}\left[3\left(\bar{V} \cdot C_{S}\right)^{(n)}-4\left(\bar{V} \cdot C_{S}\right)^{(n-1)}+\left(\bar{V} \cdot C_{S}\right)^{(n-2)}\right]=\sum_{m} J_{S}^{(n)}
\end{gathered}
$$

where index $n$ refers to time $t^{n}$ and $\Delta t$ is the time step, such that $t^{n}=t^{n-1}+\Delta t$. Thus, the equations are solved for all variables with index $n$ at time $t=t^{n}$, leaving the remaining terms as known from the former time steps. The equations are solved together with the above equations for electroneutrality and the compliance model. The strongly coupled nonlinear equations were solved to machine accuracy by a conventional iterative Newton-Raphson method. In forming the Jacobian matrix, the equations were not differentiated analytically as a simple difference scheme was employed. For analyses of transient states, the term "sampling frequency" refers to frequency of time steps. With a single time step, we jump directly from one steady state to another - skipping transient states. 


\subsection{Choice of Independent Variables}

Appendix 2 lists independent variables of the model displayed in Fig. 1b. Ion permeabilities and maximum pump rates were chosen to obtain a net uptake of $\mathrm{Na}^{+}$of about 5,000 pmol cm $\mathrm{c}^{-2} \mathrm{~s}^{-1}$ with associated volume absorption of 30 $40 \mathrm{~nL} \mathrm{~cm}{ }^{-2} \mathrm{~s}^{-1}$ together with intracellular concentrations and serosa-membrane potential in reasonable agreement with measured quantities (Windhager 1979). From measurements, $C_{\mathrm{Na}}^{\text {cell }}=17.5, C_{K}^{\text {cell }}=113$, and $C_{\mathrm{Cl}}^{\text {cell }}=18 \mathrm{mM}$ at a serosal membrane potential of $-76 \mathrm{mV}$ (Cassola et al. 1983; Edelman et al. 1978; Yoshitomi and Fromter 1985). The corresponding model values are given in Fig. 2. For simulating the somewhat low $C_{K}^{\text {cell }}$, we assumed a mean net charge of intracellular nondiffusible anions less than unity $\left(z_{A}=-0.75\right)$. In the model, the $\mathrm{Na}^{+} / \mathrm{K}^{+}$pump in the serosal plasma membrane is "silent" so that the active $\mathrm{Na}^{+}$uptake is due entirely to the activity of lateral pumps (Kashgarian et al. 1985). The major electro-diffusive $\mathrm{K}^{+}$exit from cells is through the $\mathrm{K}^{+}$channels of $l m$. Both apical and "basolateral" plasma membrane domains contain water channels (Nielsen et al. 1996). The osmotic permeabilities were taken from experiments on rabbit proximal tubule (Carpi-Medina et al. 1984; Gonzáles et al. 1984). Solvent drag on sucrose indicated that the paracellular pathway of the kidney proximal tubule contributes to water transport across the epithelium (Whittembury et al. 1988), but the hydraulic conductance of tight junctions, which constitutes the rate limiting structure along the pathway, is not easy to determine. One would think that one way of doing this would be to block water channels of the apical membrane and measure the residual transepithelial water flux. This method was applied by Whittembury's laboratory (Carpi-Medina and Whittembury 1988), and we have used the value thus estimated, $P_{o s m}^{t j}=2.5 \times 10^{3} \mu \mathrm{m} \mathrm{s}^{-1}$. As we shall see below, blocking the osmotic permeability of the apical membrane will lead to an increase in the osmolarity of lis, forcing an increased water flow along the paracellular pathway. Thus, our osmotic permeability of tight junctions is overestimated. However, as none of the conclusions, generally of semiquantitative nature, are affected by this choice, it is applied here in lack of better estimate. As emphasized above, the serosal plasma membrane contacting the epithelium's basement membrane and the lateral plasma membrane constitute two separate domains. The model is born with similar transport systems in the two domains. The serosal-membrane fluxes governing the majority of computations were obtained by choosing small values of associated independent variables.

Molecular biological and biophysical studies indicated that paracellular fluxes are mediated both by cation and anion selective tight junction pores, recently reviewed by Fromm et al. (2017). Claudin- 2 is selectively permeable for small cations like $\mathrm{Na}^{+}$and $\mathrm{K}^{+}$and permeable for water. Claudin-10a (and perhaps claudin-17) is selectively permeable for small anions like $\mathrm{Cl}^{-}$. Reflection coefficients of tight junctions were taken from literature $\sigma_{N a}^{t j}=\sigma_{K}^{t j}=0.7$ and $\sigma_{C l}^{t j}=0.45$ (Ullrich 1973). The interspace basement membrane is governed by physical properties of the basement membrane, and a morphometric study of rabbit proximal 
tubule indicating that $\mathrm{ibm}$ constitutes $10 \%$ of the basement membrane area of the entire tubule (Welling and Grantham 1972; Welling et al. 1987a, b). Ion permeability of convection pores was selected to obtain the paracellular electrical resistance estimated by Frömter (1979) of about $5 \Omega \mathrm{cm}^{2}$, which requires a relatively high $\mathrm{Cl}^{-}$permeability of delimiting membranes. The cation "selectivity" of the interspace basement membrane is that of free diffusion in water.

\subsection{Geometrical Dimensions and Units of Physical Quantities}

A stereological study of S1 segment of rabbit proximal tubule indicated an outer and inner diameter of 38 and $24 \mu \mathrm{m}$, respectively, corresponding to a cell height of $7 \mu \mathrm{m}$. Referring to $1 \mathrm{~mm}$ of tubule length, the following numbers were obtained: an epithelial volume of $6.8 \times 10^{5} \mu \mathrm{m}^{3}$, an apical membrane area of $2.20 \times 10^{6} \mu \mathrm{m}^{2}$, and a lateral membrane area of $2.29 \times 10^{6} \mu \mathrm{m}^{2}$ (Welling and Welling 1988). With 300 cells per mm (Welling et al. 1987a), single-cell volume is about 2,267 fL. With gap junctions between cells, we assume that the epithelium constitutes a continuous functional syncytium.

Physical constants, independent variables, and computed dependent variables are in MKSA units. In the text, however, all variables are presented in units commonly used in physiological literature.

\section{Results}

\subsection{General Features}

Kidney proximal tubule accomplishes isosmotic transport in absence of glucose in luminal perfusion solution (Windhager et al. 1959; Morel and Murayama 1970). Figure 2 contains values given by the model for the reference state exposed to symmetrical external glucose-free solutions. With respect to cellular ion concentrations, it is noted that $C_{K}^{\text {cell }}$ of $117 \mathrm{mM}$ is fairly low, which is in agreement with measurements, recently reviewed by Weinstein (2013): $70 \mathrm{mM}$ (Necturus), $113 \mathrm{mM}$ (rat), and $68 \mathrm{mM}$ (rabbit). The intracellular electrical potential, $V^{\text {cell }}=-82 \mathrm{mV}$, agrees with values measured in rat ranging between -64 and $-85 \mathrm{mV}$ (Frömter 1979). The lumen-negative transepithelial potential difference is no more than $V^{\text {trans }}=-1.78 \mathrm{mV}$, governed by high paracellular electrical conductance and the following transepithelial ion fluxes $\left(\right.$ pmol cm $\left.\mathrm{cm}^{-2} \mathrm{~s}^{-1}\right): J_{N a}=5,197, J_{K}=187$, and $J_{C l}=5,384$. Fluxes through the apical membrane are associated with an apical membrane resistance of $313 \Omega \mathrm{cm}^{2}$, which is 57 times larger than the shunt resistance of $5.5 \Omega \mathrm{cm}^{2}$. The corresponding values for rat are 260 and $5 \Omega \mathrm{cm}^{2}$, respectively (Frömter 1982). At transepithelial osmotic equilibrium, water uptake would have 


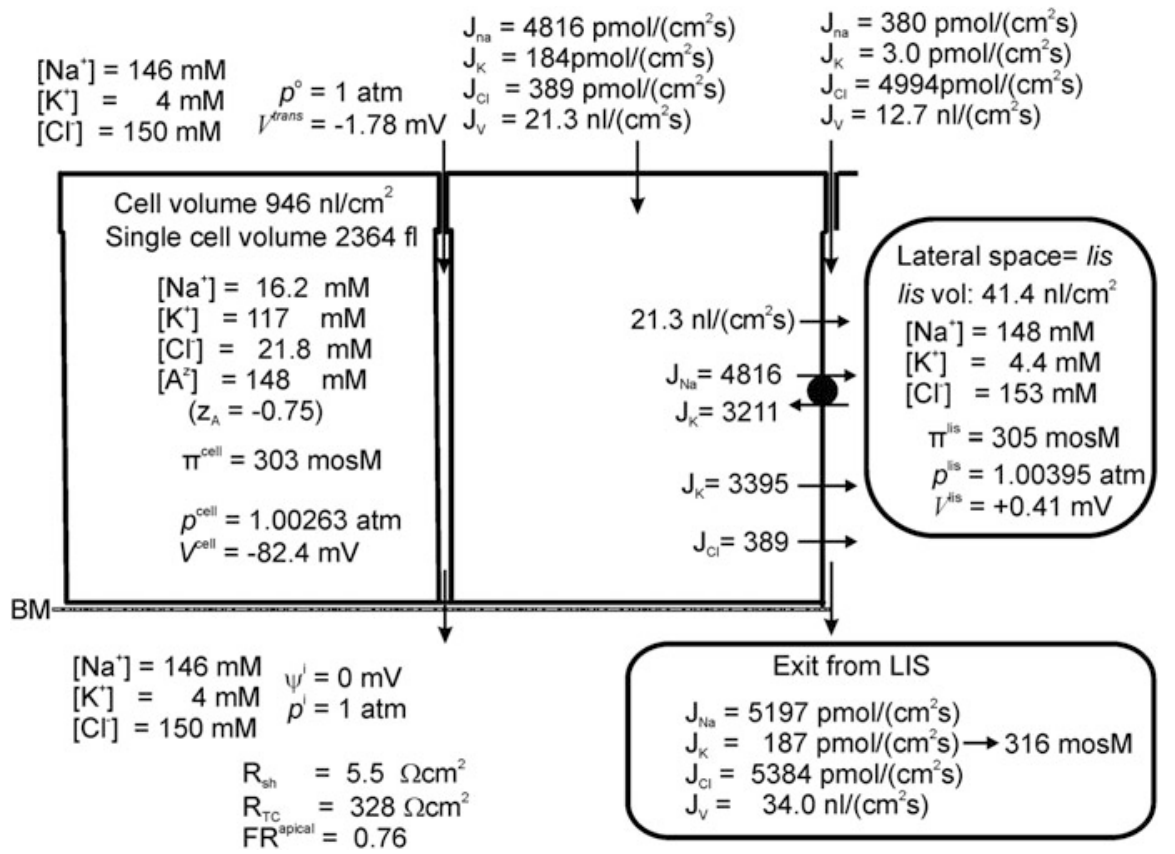

Fig. 2 Reference state of the minimalistic model epithelium. With the large osmotic permeabilities estimated experimentally (Carpi-Medina et al. 1984; Gonzáles et al. 1984) is the fluid exiting the lateral intercellular space predicted to be hyperosmotic to bath: 316 mosM versus 300 mosM. Electrical resistances given by the model: $R^{a m}=313 \Omega \mathrm{cm}^{2}, R^{l m}=15.9 \Omega \mathrm{cm}^{2}, R^{t j}=4.43 \Omega \mathrm{cm}^{2}$, and $R^{i b m}=1.10 \Omega \mathrm{cm}^{2}$. FR ${ }^{\text {apical }}$ is the ratio of apical (luminal) membrane resistance to transepithelial resistance

to be translateral, and with osmotic permeabilities obtained in experiments by Carpi-Medina and Whittembury (1988), the water uptake via apical membrane is $21.3 \mathrm{~nL} \mathrm{~cm}^{-2} \mathrm{~s}^{-1}$. This is about twice the water flux of $12.7 \mathrm{~nL} \mathrm{~cm}^{-2} \mathrm{~s}^{-1}$ through tight junctions, which is driven by $\Delta \pi=5$ mosM. Convection fluxes energized by paracellular water absorption are discussed in detail below. Here it suffices to point out that paracellular solvent drag on potassium ions cannot account for transtubular $\mathrm{K}^{+}$absorption which provides a $\mathrm{K}^{+}$concentration of the absorbate that is significantly less than $1 \mathrm{mM}$; an estimate using numbers of Fig. 2 would give $3.0 \mathrm{pmol} \mathrm{cm} \mathrm{c}^{-2} \mathrm{~s}^{-1} / 22.7 \mathrm{nl} \mathrm{cm}^{-2} \mathrm{~s}^{-1}=0.24 \mathrm{mM}$. This should be compared to the total $\mathrm{K}^{+}$absorption that gives a $\mathrm{K}^{+}$concentration of the absorbate of $187 / 34.0=5.5 \mathrm{mM}$ (Fig. 2), that is, a value much closer to the $4 \mathrm{mM}$ of the serosal bath. When glucose absorption is included, this number drops to $\left[\mathrm{K}^{+}\right]_{\text {absorbate }}=190 \mathrm{pmol} \mathrm{cm}{ }^{-2} \mathrm{nl} / 46 \mathrm{nl} \mathrm{cm}{ }^{-2}=4.1 \mathrm{mM}$, see Fig. 4. Exit of water through the interspace basement membrane of low reflection coefficients is driven by a small hydrostatic pressure difference $\left(p^{l i s}-p^{i}\right)$ of $3.95 \times 10^{-3} \mathrm{~atm}$. With a total apical water uptake of $J_{V}=34.0 \mathrm{~nL} \mathrm{~cm}^{-2} \mathrm{~s}^{-1}$ at steady state, this is also the volume flux across $i b m$. The lateral intercellular space of an osmolarity of 305 mosM is no 
more than $1.7 \%$ hyperosmotic relative to the symmetrical bathing solutions of 300 mosM. Nevertheless, the fluid exiting the lateral space of 316 mosM is $5.3 \%$ hyperosmotic with respect to bath. The difference in osmolarity between lis and the fluid emerging from lis, in this example 11 mosM, shows that exit fluxes are governed by relatively large electrodiffusion permeabilities of ibm (conf. Eq. 6), which exposes the unavoidable diffusion-convection problem of the exit pathway in isosmotic transport.

\subsection{A Component of $\mathrm{Na}^{+}$Uptake Bypasses the Pump}

Although the electrical driving force for $\mathrm{Na}^{+}$movement through tight junctions is $-2.19 \mathrm{mV}$, the flux of $\mathrm{Na}^{+}$of $380 \mathrm{pmol} \mathrm{cm}^{-2} \mathrm{~s}^{-1}$ is inward showing that solvent drag overrules the electrochemical driving force of opposite direction. Formally, the $\mathrm{Na}^{+}$current through tight junctions can be written,

$$
I_{N a}^{t j}=G_{N a}^{t j}\left(V^{t j}-E_{N a}^{t j}+\Phi_{N a}^{t j}\right)
$$

$G_{N a}^{t j}$ is the $\mathrm{Na}^{+}$conductance of tight junctions, $E_{\mathrm{Na}}^{t j}$ the $\mathrm{Na}^{+}$equilibrium potential across tight junctions, $V^{t j}$ the transjunctional potential difference, and $\Phi_{N a}^{t j}$ the driving force due to convection, which Ussing has given the expressive term "solvent drag." In the electrodiffusion-convection regime, the term denoted $\Phi_{\mathrm{Na}}^{t j}$ of Eq. (24) is the driving force resulting from the convection process. Because we here consider an ion current, it follows that its dimension is "volt." Ussing's original mathematical treatment of solvent drag concerned unidirectional isotope fluxes of electroneutral molecules that included a hydrostatic pressure gradient as driving force for the net water flux. With this in mind, it should be evident that our treatment of solvent drag agrees with the original definition. Aiming at solvent drag:

$$
\Phi_{N a}^{t j}=\frac{I_{N a}^{t j}-G_{N a}^{t j}\left(V^{t j}-E_{N a}^{t j}\right)}{G_{N a}^{t j}}
$$

There is strong dependence of $\Phi_{N a}^{t j}$ on $P_{N a}^{t j}$ (see Table 1). However, unlike paracellular transport, the overall tubule function is insensitive to a $10 \times$ decrease in $P_{N a}^{t j}$, which on the other hand leads to 11.3 times increase in paracellular solvent drag. Thus, even though the transepithelial potential difference is negative, our quantitative analysis predicts that solvent drag in tight junctions prevents passive back leak of $\mathrm{Na}^{+}$to tubule lumen, which is contrary to information given in medical textbooks (Boron and Boulpaep 2017). 


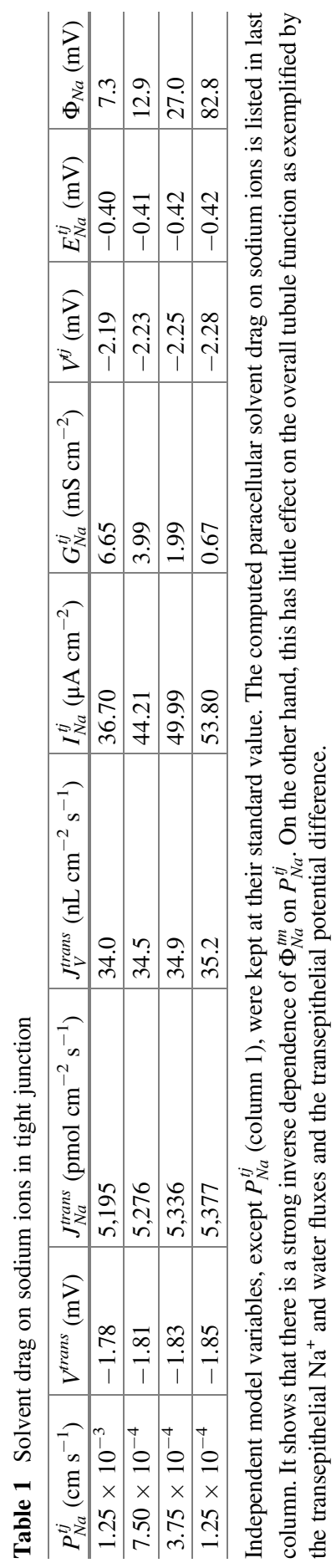



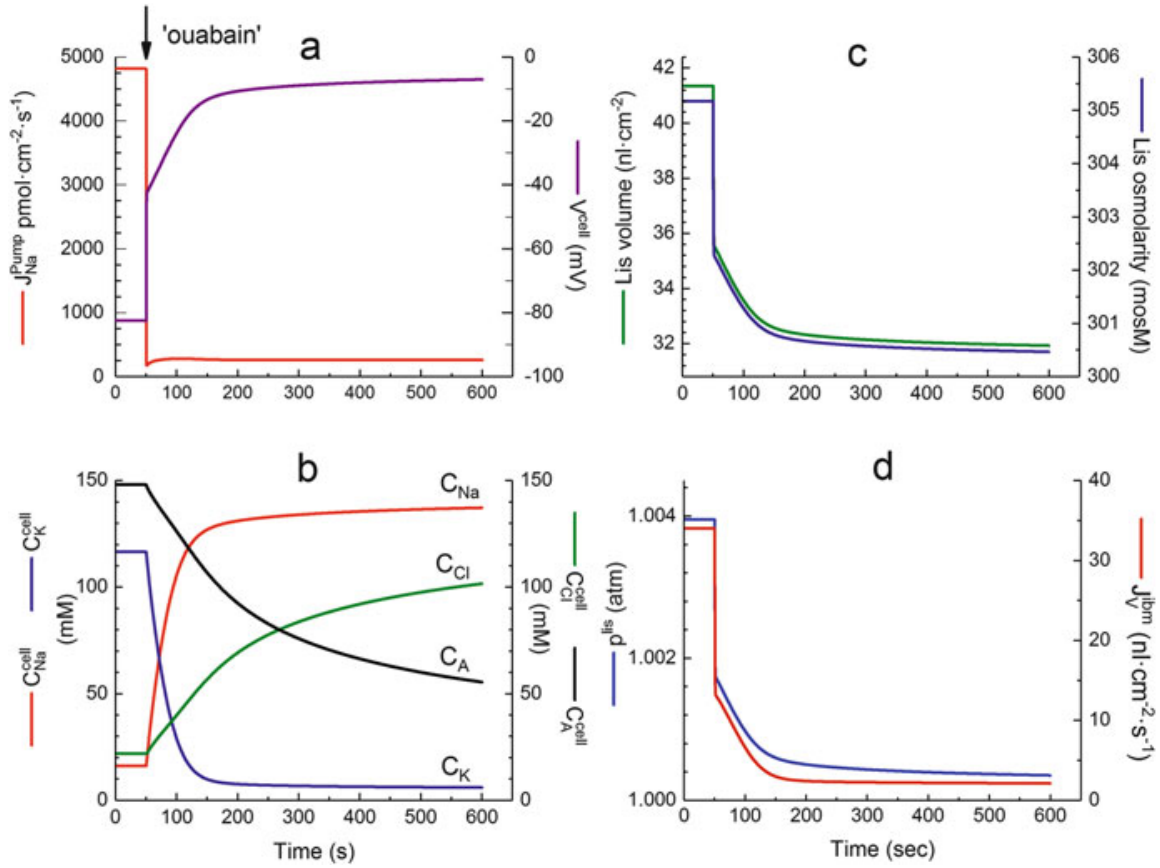

Fig. 3 (a-d) Effects of inhibition of the $\mathrm{Na}^{+}-\mathrm{K}^{+}$-ATPase of lateral membrane. (a) at time $=50 \mathrm{~s}$, maximum pump flux (Eq. 4a) was reduced exponentially $(\tau=0.1 \mathrm{~s}$, Eq. 25$)$ by a factor of $50 \times$. This resulted in fast drop of $J_{\mathrm{Na}}^{\text {pump, } l m}$ and an associated fast cell depolarization of $40 \mathrm{mV}$. The further slow depolarization owes to dissipation of ion gradients at rates given by respective membrane permeabilities and cellular ion pool sizes. (b) Cation-gradient dissipations lead to $\mathrm{Na}^{+}$and $\mathrm{Cl}^{-}$ accumulation and $\mathrm{K}^{+}$loss. The net effect is cell swelling as indicated by the decrease in concentration of nondiffusible intracellular anions $\left(C_{A}\right)$. (c) As consequence of the arrest of lateral active $\mathrm{Na}^{+}$flux and subsequent slow ion-gradient dissipations, volume and osmolarity of lis decrease accordingly. (d) The associated drop in hydrostatic pressure directs reduced exit of fluid across the interspace basement membrane

\subsection{Inhibition of the $\mathrm{Na}^{+} / \mathrm{K}^{+}$Pump}

The lateral $\mathrm{Na}^{+} / \mathrm{K}^{+}$-ATPase energizes ion and water fluxes through the epithelium (Garg et al. 1981; Gyory and Kinne 1971), and owing to the very high expression of the enzyme in proximal tubule (Jørgensen 1986), pump currents may have significant electrophysiological and hydrodynamic effects. Inhibiting the $\mathrm{Na}^{+} / \mathrm{K}^{+}$ pump by a $50 \times$ reduction of $P_{N a^{+}, K^{+}}^{l m}$ (Eq. 4a) is shown in Fig. 3. The time course of inhibition is given by,

$$
c(t)=c(\infty)-(c(0)-c(\infty)) \exp (-t / \tau)
$$

Here, $c(0) / c(\infty)=50$ and $\tau=0.1 \mathrm{~s}$. Due to the voltage dependence of the pump current, the instantaneous membrane depolarization is fast and large. Computations 
given by the model (Fig. 3a) predict an ouabain-induced cell depolarization of $40 \mathrm{mV}$ for a pump current of $155 \mu \mathrm{A} \mathrm{cm}{ }^{-2}$. This is to be compared to a pumpgenerated hyperpolarization of $15-20 \mathrm{mV}$ of the inward facing membrane of frog skin for pump currents of $40-50 \mu \mathrm{A} \mathrm{cm}{ }^{-2}$ (Nagel 1980), and a $1.8 \mathrm{mV}$ hyperpolarization of giant axon caused by a pump current of $1.8 \mu \mathrm{A} \mathrm{cm}^{-2}$ (Hodgkin and Keynes 1955). Our conclusion here is that the contribution of the pump current to the membrane potential has evolved for serving tissue specific functions of the $\mathrm{Na}^{+} / \mathrm{K}^{+}$ pump; in proximal tubule, the pump serves the returning of a large volume of isosmotic fluid to the extracellular fluid which requires high activity of the $\mathrm{Na}^{+} / \mathrm{K}^{+}$-ATPase. In the skin of frogs on land the function of the sodium pump is to return $\mathrm{Na}^{+}$(and $\mathrm{Cl}^{-}$) to the body fluids during evaporative water loss from the cutaneous surface fluid generated by subepidermal mucous glands (Larsen 2011). Finally, electrical signalling in excitable cells relies on the membrane potential being uniquely given by the ratio of the membrane's $\mathrm{Na}^{+}$and $\mathrm{K}^{+}$permeabilities (Hodgkin 1958), which presupposes relatively very low activity of the $\mathrm{Na}^{+} / \mathrm{K}^{+}$-ATPase. Secondary to the voltage dependent sudden decrease, the pump flux decreases further but with a longer time constant caused by the relatively slow redistribution of cellular cation pools (Fig. 3b). With negatively charged intracellular macroions, the working of the pump keeps the cell from swelling and bursting, which otherwise would take place due to the continuous inflow of $\mathrm{Na}^{+}$(and $\mathrm{Cl}^{-}$), conf. the theory of Gibbs-Donnan equilibrium (Sten-Knudsen 2002). Thus, concomitant with accumulation of cellular $\mathrm{Na}^{+}$and $\mathrm{Cl}^{-}$, the cell swells (Fig. 3b). The sudden reduction in pumping of $\mathrm{Na}^{+}$into the lateral intercellular space and the slow cellular ion gradient dissipations result in reduction in osmolarity and volume of lis that takes place with similar fast and slow time courses (Fig. 3c). The coupling of the pump flux and the water flow across the lateral membrane as indicated in Fig. 3c is discussed in detail in Sect. 3.5. The rate of exit of fluid into the serosal compartment is governed by the hydrostatic pressure difference between the lateral intercellular space, $p$ lis, and serosal compartment, $p^{i}$ of 1 atm (Fig. 3d).

\subsection{Effect of Adding Glucose}

Sodium and water absorption increase significantly together with apical membrane depolarization if organic solutes are added to the tubular perfusion solution (Lapointe and Duplain 1991). In rabbit and rat proximal convoluted tubules, significant effects on the rate of fluid absorption were observed upon removal of luminal glucose and other metabolites (Burg et al. 1976; Frömter 1982). We have chosen values of independent variables governing apical $\mathrm{Na}^{+}$uptake (Eqs. 1a-3a) for reproducing studies simulating the abovementioned significant effects of glucose. Thus, in the following, fluxes carried by Eq. (3a) are significant as compared to fluxes generated by Eqs. (1a) and (2a). The computed steady state with the physiological concentration of $5 \mathrm{mM}$ glucose is shown in Fig. 4. The pertinent findings can be summarized. In steady state, the cellular glucose concentration is about twice that of the external concentration. Compared to Fig. 2 with no glucose, $C_{N a}^{c e l l}$ is increased while $C_{K}^{\text {cell }}$ is decreased, leading to $3 \%$ cell swelling from 2,366 to $2,436 \mathrm{fL}$. Such a 


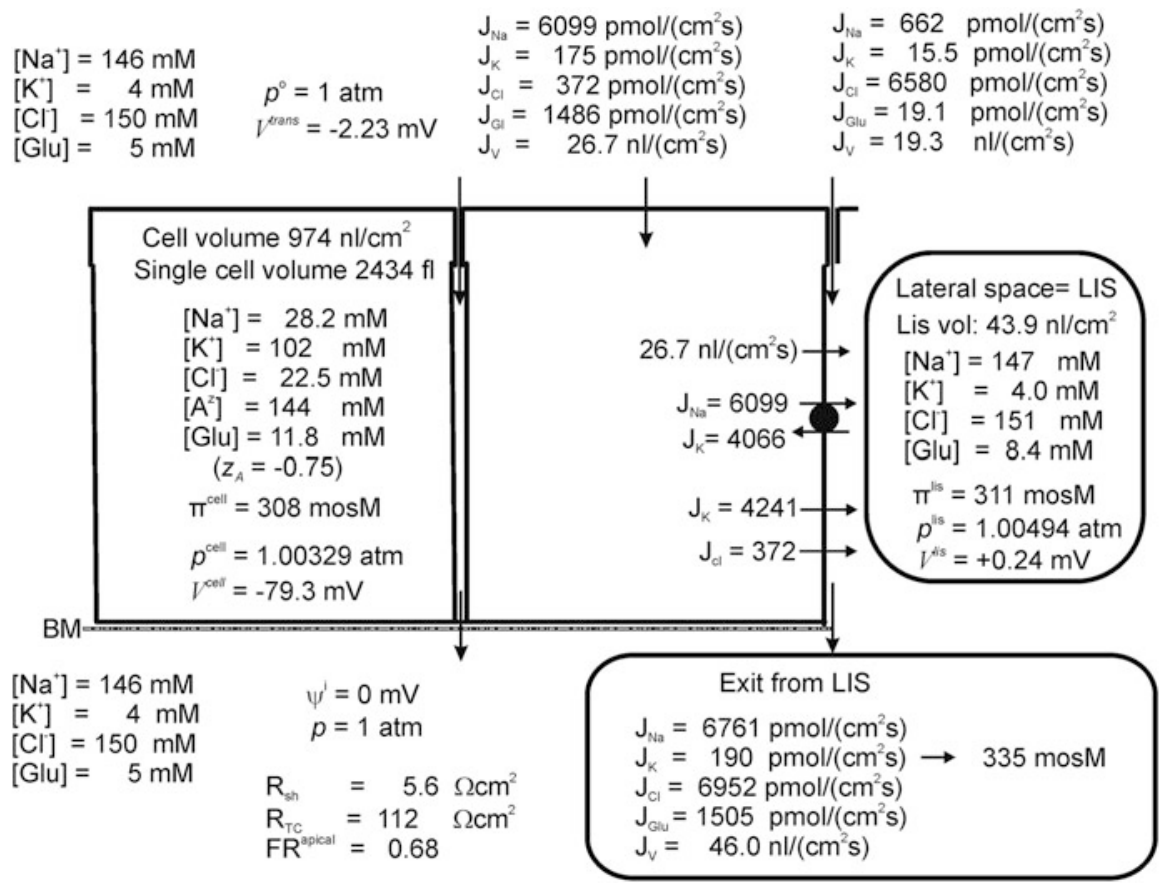

Fig. 4 The model epithelium engaged in glucose absorption. The glucose uptake across the luminal membrane is coupled to uptake of sodium ions and driven by the electrochemical gradient for $\mathrm{Na}^{+}$ (SGLT2, Eq. 3a). Therefore, addition of glucose to external baths results in stimulation of the active $\mathrm{Na}^{+}$flux across the lateral membrane from 4,816 (Fig. 2) to $6,099 \mathrm{pmol} \mathrm{cm}^{-2} \mathrm{~s}^{-1}$. The enhanced lateral $\mathrm{Na}^{+}$pump flux increases the $\mathrm{Na}^{+}$concentration and osmolarity of the lateral intercellular space, which in turn increases transepithelial fluid uptake, from 30 to $46 \mathrm{~nL} \mathrm{~cm}^{-2} \mathrm{~s}^{-1}$. Importantly, this results in an increase in the hyperosmolarity of transported fluid, from 316 to 335 mosM. Electrical resistances given by the model: $R^{a m}=96.5 \Omega \mathrm{cm}^{2}, R^{l m}=17.3 \Omega \mathrm{cm}^{2}, R^{t j}=4.45 \Omega \mathrm{cm}^{2}$, and $R^{i b m}=1.10 \Omega \mathrm{cm}^{2}$

small cell volume change indicates a priori an insignificant increase in intracellular chloride concentration, which is confirmed quantitatively by numbers given by the model, $C_{C l}^{c e l l}=21.8$ and $22.5 \mathrm{mM}$, respectively. The glucose-induced hyperpolarization of the transepithelial potential difference of $-0.45 \mathrm{mV}$ from -1.78 to $-2.23 \mathrm{mV}$, compare Fig. 2 with Fig. 4, is comparable in absolute magnitude to that of rat proximal tubule, $-0.36 \pm 0.22 \mathrm{mV}$, mean \pm S.D. (Frömter 1982). In the same study, Frömter perfused rat tubule in situ with Ringer's solution containing $30 \mathrm{mM}$ bicarbonate in the perfusion solution. Prior to glucose, the transepithelial potential difference was lumen positive but becoming lumen negative, as predicted by model computation, when perfused with $3 \mathrm{mM}$ glucose. The stimulated sodium pump flux results in increased osmolarity of lis together with an increased water uptake from 34 to $46 \mathrm{~nL} \mathrm{~cm} \mathrm{~s}^{-2}$. The deviation $(\Delta)$ from isosmotic transport becomes significantly larger following addition of glucose, i.e., $\Delta=16 \operatorname{mos} \mathrm{M}$ and $\Delta=29$ mosM as indicated in Figs. 2 and 4. The increased fluid uptake discussed above includes an increased flow of fluid in tight junctions, from 12.7 to 

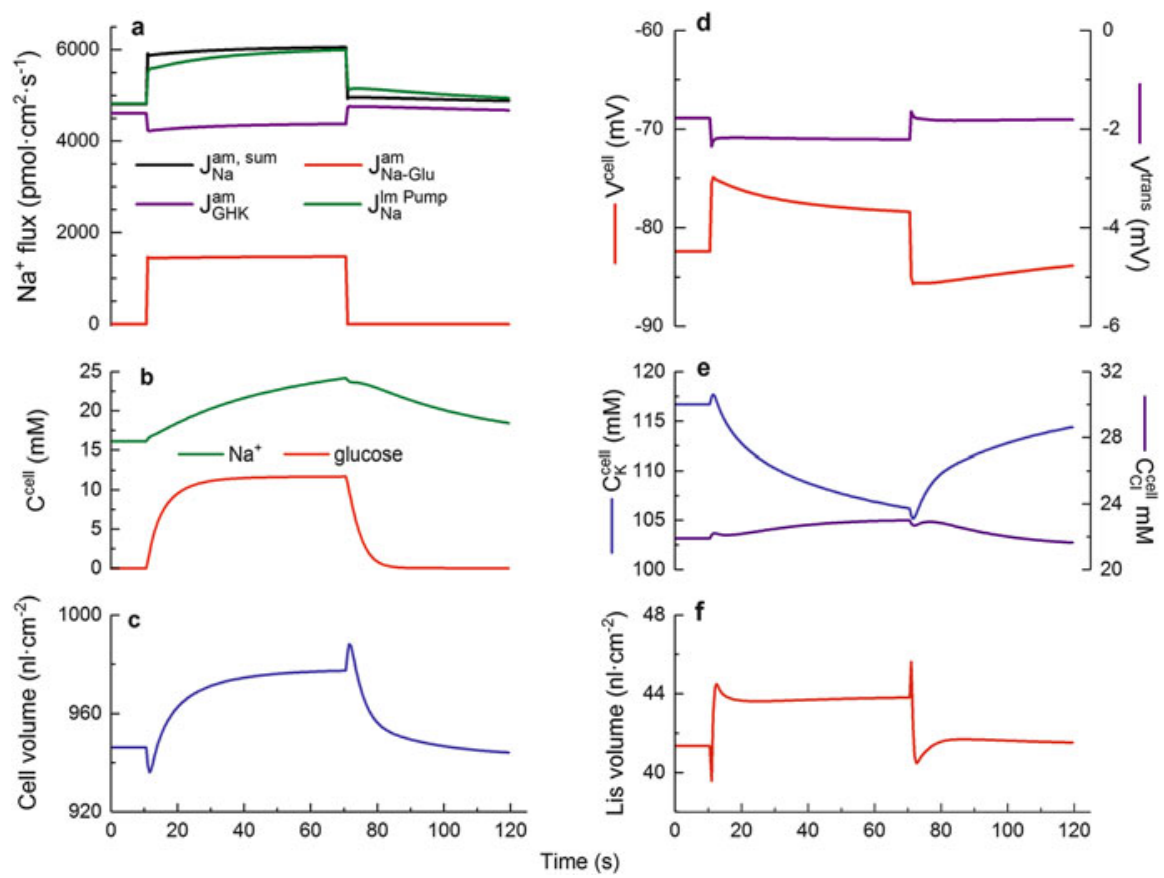

Fig. 5 (a-f) Effects of reversible bilateral exposure of $5 \mathrm{mM}$ glucose of $60 \mathrm{~s}$ duration. (a) Fluxes carried by electrogenic $\mathrm{Na}^{+}$pathways $J_{\mathrm{Na}}^{a m, \text { sum }}=J_{\mathrm{GHK}}^{a m}+J_{\mathrm{Na}-\mathrm{Glu}}^{\mathrm{am}}$. Note initial decrease in GHK-flux caused by depolarization of apical membrane. $J_{\mathrm{Na}}^{\mathrm{pump}, l m}$ is stimulated "instantly" and secondarily as a consequence of a slow increase in $C_{N a}^{\text {cell }}$. See text for discussion. (b) Inflow of $\mathrm{Na}^{+}$and glucose results in cellular accumulation of the two solutes, but steady state is not achieved for $\mathrm{Na}^{+}$within the 60-s glucose pulse. (c) Cell swelling due to accumulation of $\mathrm{Na}^{+}$and glucose is preceded by fast volume decrease caused by the osmotic effect of adding glucose. (d) The electrogenic nature of the apical Na-glucose transporter is reflected in significant membrane depolarization and associated small hyperpolarization of $V^{\text {trans }}$. (e) $C_{K}^{\text {cell }}$ decreases with long time constant, e.g., at steady state is $C_{K}^{\text {cell }}=102 \mathrm{mM}$ (Fig. 4), while increase in $C_{C l}^{\text {cell }}$ is modest. (f) The relatively small lis volume responds near instantly to adding/removing glucose to external compartments that embrace the steady volume increase caused by an increase in $C_{\text {glucose }}^{\text {lis }}$ to $8.4 \mathrm{mM}$ (Fig. 4)

$19.3 \mathrm{~nL} \mathrm{~cm}^{-2} \mathrm{~s}^{-1}$, which results from increased osmolarity of lis from 305 to 311 mosM. Due to convection, this has direct effect on cation fluxes in tight junctions; e.g., for $P_{N a}^{t j}=1.25 \times 10^{-3} \mathrm{~cm} \mathrm{~s}^{-1}$ is $J_{N a}^{t j}$ increased from 380 to $662 \mathrm{pmol} \mathrm{cm} \mathrm{cm}^{-2} \mathrm{~s}^{-1}$. The number of $662 \mathrm{pmol} \mathrm{cm}^{-2} \mathrm{~s}^{-1}$ obtained with glucose in luminal solution is probably the better estimate of the paracellular $\mathrm{Na}^{+}$reabsorption driven by solvent drag in proximal convoluted tubule.

In Fig. 5 are shown time-dependent states induced by 60 -s bilateral exposure to $5 \mathrm{mM}$-glucose. By choosing $\tau=0.1 \mathrm{~s}$ (Eq. 25), the time course of cell variables given in Fig. 5 is reflecting characteristic times of intracellular pools of the "functional syncytium." Due to the electrogenic nature of the apical $\mathrm{Na}^{+}$-glucose transporter (Eq. 3a), the cell membrane potential depolarizes by $7 \mathrm{mV}$ (Fig. 5d), which is comparable to $5.7 \mathrm{mV} \pm 2.0$ in rat (Frömter 1982). In the same study, 
Frömter found that the resistance of the brush border membrane decreased to $52.8 \pm 12 \%$ (mean $\pm \mathrm{SD}$ ) of its control value. In the model, apical membrane resistance dropped from 313 to $96 \Omega \mathrm{cm}^{2}$, i.e., to $31 \%$ of the control value. A plausible reason for the difference between experiment and computation is that Frömter had $3 \mathrm{mM}$ glucose in the luminal perfusion solution as compared to our $5 \mathrm{mM}$ glucose (Eq. 3a). Thus, with $3 \mathrm{mM}$ glucose, the computed apical membrane resistance dropped to $46 \%$ of the control value which is within the abovementioned experimental range (details not shown). As a novel result, it should be noted that the addition of glucose also leads to "instantaneous" increase in $J_{\mathrm{Na}}^{\text {lm, pump }}$ (Fig. 5a, green graph) which is the consequence of the pump current being an instantaneous function of lateral membrane potential (Eq. 4a). The effect of activating rheogenic $\mathrm{Na}^{+}$uptake across the apical membranes on $\mathrm{Na}^{+}$pumping rate at the lateral membrane and the associated enhanced rate of fluid uptake constitute a mechanism of "cross-talk" that is not described before. The depolarization is about the same for apical and lateral membranes, because the cell is "short-circuited" by the low-resistance paracellular shunt, cf. time course of $V^{\text {trans }}$ shown in Fig. 5d. Subsequently, $J_{\mathrm{Na}}^{\text {lm, pump }}$ increases slowly governed by slow increase in $C_{\mathrm{Na}}^{\text {cell }}$ (Fig. 5b).

The cell depolarization indicated in Fig. 5d decreases the $\mathrm{Na}^{+}$flux in apical GHK-rectifying $\mathrm{Na}^{+}$channels, conf. Eq. (1a) (Fig. 5a purple graph). In recordings of the total membrane current, this would be masked by the larger $\mathrm{Na}^{+}$flux via the $\mathrm{Na}^{+}$-glucose transporter (Fig. 5a). The decrease in $C_{K}^{\text {cell }}$ from 116 to $106 \mathrm{mM}$ (Fig. 5e), concomitant with the increase in $C_{N a}^{c e l l}$, should be compared with the small cell swelling mentioned above, which by and large is caused by the accumulated electroneutral glucose (Fig. 5b, e). This conclusion is in agreement with microscopically observed cell volume changes in microperfused proximal convoluted tubule of rabbit kidney (Burg et al. 1976).

In conclusion, the model reproduces measured glucose effects on $\mathrm{Na}^{+}$fluxes, electrophysiology, and cell volume. Besides stimulated transepithelial $\mathrm{Na}^{+}$and glucose fluxes fluid uptake as well is increased. It is noteworthy that the solutecoupled fluid flux is predicted to become more hyperosmotic when the proximal kidney tubule is engaged in glucose reabsorption, i.e., 316 mosM versus 335 mosM, which should be compared to "bath" osmolarities of 300 and 305 mosM, respectively.

\subsection{Blocking Water Channels of Apical Membrane}

Reducing the osmotic permeability of the apical membrane from $0.449 \times 10^{4}$ to $0.449 \mu \mathrm{m} \mathrm{s}^{-1}$ results in elimination of translateral water flow with hardly detectable effects on rate of active $\mathrm{Na}^{+}$uptake and overall transepithelial water absorption, the latter being 34.0 and $35.5 \mathrm{~nL} \mathrm{~cm}^{-2} \mathrm{~s}^{-1}$, respectively (Figs. 2 and 6). At the new steady state with little change in apical flux of sodium ions, the pumping of $\mathrm{Na}^{+}$into lis is also changed by a small amount by the above maneuver, $J_{\mathrm{Na}}^{\text {lm, pump }}=4,816$ and $4,837 \mathrm{pmol} \mathrm{cm}{ }^{-2} \cdot \mathrm{s}^{-1}$, respectively (Figs. 2 and 6). Water is now forced to take the paracellular route. Osmolarity and hydrostatic pressure of lis, governing entrance 


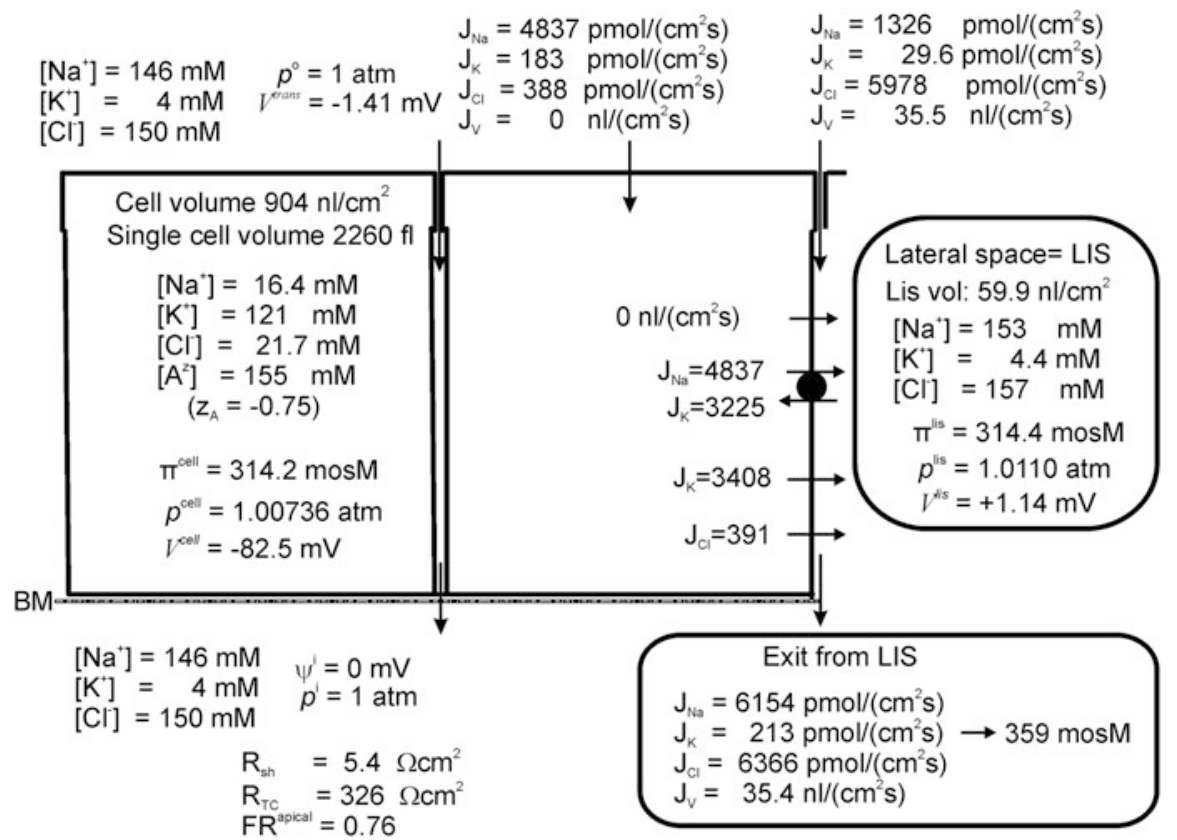

Fig. 6 Steady-state solution with eliminated apical osmotic permeability. Apical $P_{f}$ was reduced by a factor of $10^{4}$ from $0.449 \times 10^{4}$ to $0.449 \mu \mathrm{m} \mathrm{s}^{-1}$. At transepithelial osmotic equilibrium, this eliminates cellular water transport, thus simulating AQP-1 (-/-). Electrical resistances given by the following models: $R^{a m}=312 \Omega \mathrm{cm}^{2}, R^{l m}=14.3 \Omega \mathrm{cm}^{2}, R^{t j}=4.37 \Omega \mathrm{cm}^{2}$, and $R^{i b m}=1.08 \Omega \mathrm{cm}^{2}$. It is important to note that the transepithelial water flux is not significantly reduced by eliminating the apical membrane's water channels, $J_{V}^{i b m}=34.0$ and $35.4 \mathrm{~nL} \mathrm{~cm}^{-2} \mathrm{~s}^{-1}$, respectively (Figs. 2 and 5)

and exit of water across tight junction and interspace basement membrane, respectively, energize the significantly increased water flux along the paracellular route. The larger ion concentrations of lis result in increased convection-electrodiffusion fluxes through ibm as reflected in the increased osmolarity to $359 \operatorname{mos} \mathrm{M}$ of the fluid emerging from lis (Fig. 6).

The relationships described above can be analyzed in detail by inspecting timedependent states following a mono-exponential reduction of $P_{f}^{a m}$ from $0.449 \times 10^{4}$ to $0.449 \mu \mathrm{m} / \mathrm{s}$ governed by $\tau=1 \mathrm{~s}$ (Eq. 25); see Fig. 7a-f. The initial response to "eliminating" the apical water permeability is a shift of water volume from cells to lis driven by the difference in osmolarity between the two compartments, which is maintained by pumping of $\mathrm{Na}^{+}$into lis (Fig. 7a). In the beginning, where volume shift is fast, $C_{N a}^{c e l l}$ increases rapidly, whereby the $\mathrm{Na}^{+}$pump flux is transiently stimulated (Fig. 7b). This lasts for about $20 \mathrm{~s}$, where the osmolarity of lis of a relatively small volume increases toward its new steady-state value. While $C_{C l}^{c e l l}$ increases transiently, the concentration of nondiffusible anions increases in parallel with loss of cell volume (Fig. 7c). The increase in osmolarity of lis drives fluid into lis from the luminal solution (Fig. 7d), which brings ions into the compartment by solvent drag (Eq. 6). At the beginning of lis-volume expansion, $p^{\text {lis }}$ is too low for 

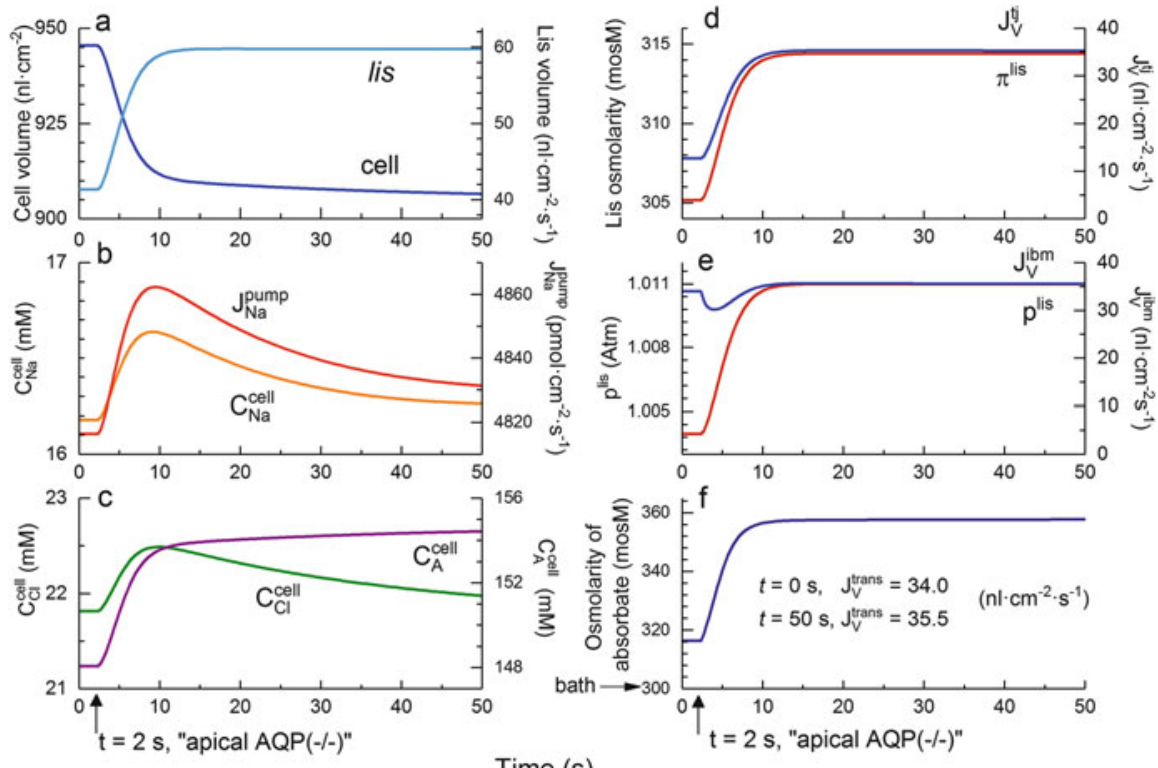

Time (s)

Fig. 7 (a-f) Time course of physiological variables in response to "eliminating" osmotic permeability of apical membrane. At time $=2 \mathrm{~s}$ and governed by $\tau=1 \mathrm{~s}, P_{f}^{a m}$ was reduced exponentially from 4,490 to $0.449 \mu \mathrm{m} \mathrm{s}^{-1}$. (a) this results in a fast shift of water volume from cells to lis. (b) $C_{N a}^{\text {cell }}$ increases transiently, which stimulates $\mathrm{Na}^{+}$pump flux, $J_{\mathrm{Na}}^{\text {pump, } l m}$. (c) While the transient increase in $C_{C l}^{c e l l}$ parallels the transient increase in $C_{N a}^{c e l l}$, the increase in concentration of nondiffusible anions is closely following the loss of cell volume. (d) The water flux is redirected from being translateral to being paracellular driven by the increased osmolarity of lis governed by the $C_{N a}^{\text {cell }}$-stimulated increase in $J_{\mathrm{Na}}^{\text {pump } l m}$. (e) Due to inflow of water, the hydrostatic pressure of lis increases, which drives the volume flux across the interspace basement membrane $J_{V}^{i b m}$. (f) The final result is a significant increase in osmolarity of the fluid emerging from lis due to convection-electrodiffusion of solutes across the interspace basement membrane (Eq. 6). Notably, at the new steady state, the transepithelial water flux is about the same as the water flux prior to eliminating $P_{f}^{a m}$ (35.5 versus $34.0 \mathrm{~nL} \mathrm{~cm}^{-2} \mathrm{~s}^{-1}$ )

preventing a decrease in the flux of fluid across ibm, $J_{V}^{i b m}$, conf. Eq. (9b) (Fig. 7e). This is transient, however; the continued influx of fluid across tight junction causes $p^{l i s}$ to increase, which enhances the fluid efflux across $i b m$ into the serosal compartment. The new steady state is reached when $J_{V}^{i b m}$ matches $J_{V}^{t m}$ (Fig. 7e, $J_{V}^{l m}=0$ at all times). The significantly increased solute concentrations of lis combined with relatively large ion diffusion permeabilities of $\mathrm{ibm}$ (Eq. 6) causes the osmolarity of the fluid exiting the epithelium to increase to 359 mosM, which now becomes hyperosmotic by 59 mosM.

With isosmotic luminal perfusate and bath solutions, Schnermann et al. (1998) found that the fluid absorption rate in the S2 portion was halved in AQP-1 knock-out [-/-] mice; expressed in $\mathrm{nL}$ per $\mathrm{mm}$ tubule length, the rate dropped from $0.64 \pm 0.15$ (wild type, $n=8)$ to $0.31 \pm 0.12(-/-, n=5)$. Our analysis presented 

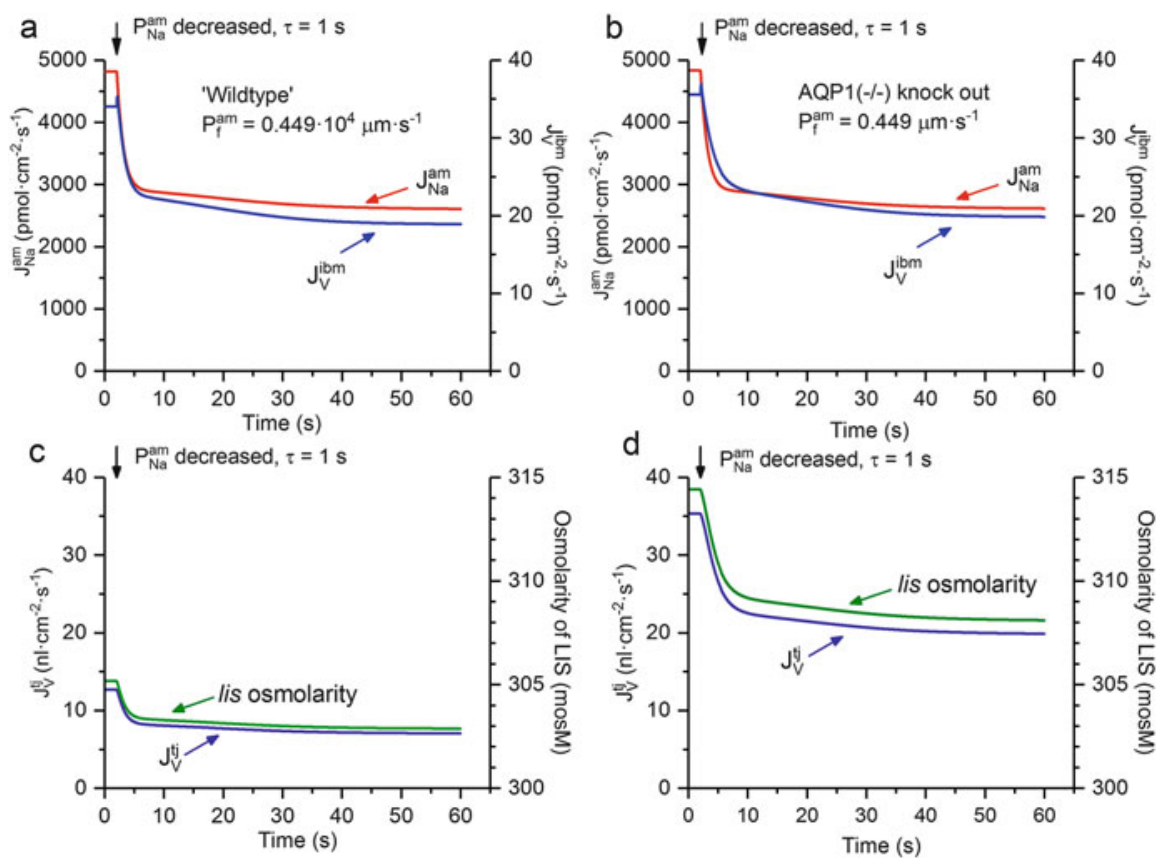

Fig. 8 (a-d) Effects of reducing apical $P_{N a}$ on water fluxes. Reducing apical entrance permeability of sodium ions ( $\tau=1 \mathrm{~s}$, text Eq. 25) results in parallel decreases in $\mathrm{Na}^{+}$flux and rate of transepithelial water absorption. This response is independent of the pathway taken by water. (a) Water absorption is both translateral and transjunctional. (b) About similar responses are seen after having reduced apical osmotic permeability. (c) In "wild type" with intact osmotic permeability of the apical membrane, the small paracellular water uptake is driven by a relatively small difference in osmolarity between surrounding solutions of $300 \operatorname{mosM}$ and lis. (d) With the translateral water uptake eliminated, all of the water enters the epithelium through tight junctions, which requires larger osmotic driving force

above showed that a very significant reduction in the number of water channels of the luminal membrane effectively eliminated cellular water fluxes but did not per se reduce the transepithelial absorption of water when studied at transepithelial osmotic equilibrium, where the rate of transepithelial water uptake as found by Solomon's group (Windhager et al. 1959) is being directed by the rate of active $\mathrm{Na}^{+}$uptake. Therefore, it might well be that the observed significant reduction in fluid absorption in AQP-1(-/-) mice observed by Schnermann et al. (1998) would have to be ascribed to the authors' concomitantly reported reduction in active $\mathrm{Na}^{+}$ absorption. For testing this hypothesis, we studied the effect of reducing the rate of $\mathrm{Na}^{+}$absorption on transtubular water absorption; see Fig. 8. Wild type and AQP-1 knock-out show similar reduction in rate of fluid uptake in response to reduction in the rate of transepithelial $\mathrm{Na}^{+}$uptake, here expressed as volume flow out of lis, cf. the time course of $J_{V}^{i b m}$ in Fig. 8a, b. The transepithelial water flow in Fig. 8b is entirely paracellular so the lack of translateral water uptake is reflected in an increased transjunctional water flux and osmolarity of lis, compare Fig. 8d with Fig. 8c. 


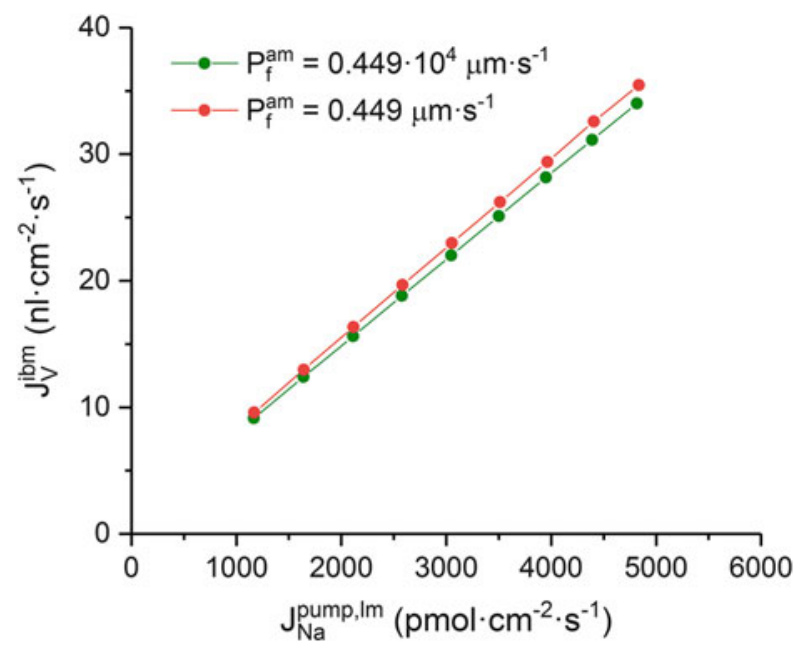

Fig. 9 The fundamental dependence of rate of water absorption on lateral active $\mathrm{Na}^{+}$flux. The rate of water absorption is governed by the rate at which $\mathrm{Na}^{+}$ions are pumped into the lateral intercellular space independently of the pathway taken by water, mostly translateral (red) or purely transjunctional (green)

The decisive influence on water absorption of the rate of active $\mathrm{Na}^{+}$flux across the lateral membrane is well documented by the computed relationships between transepithelial water uptake and the rate of pumping of $\mathrm{Na}^{+}$into the lateral space in wild type and apical AQP-1 knock-out, respectively; see Fig. 9.

\subsection{Volume Response of the Epithelium to a Luminal Osmotic Pulse}

Exposure of the epithelium to a luminal hyperosmotic pulse results in reversible cell shrinkage (Fig. 10a, b). This is similar to rabbit proximal straight tubule, which does not exhibit volume regulatory increase (Kirk et al. 1987). Volume of the lateral intercellular space increases (Fig. 10c), reflecting that the influx of water from cells to lis exceeds the efflux of water to luminal bath through tight junctions. The explanation for this is obvious: the osmotic water permeability of apical and lateral plasma membranes is larger than that of tight junctions; there is, therefore, a flow of water from cells to lis, which swells. The loss of cell volume is quantitatively reflected in the increase in concentration of nondiffusible anions (Fig. 10d), a principle that was applied by Reuss (1985) for real-time monitoring of volume changes of epithelial cells in studies of cell volume regulation. The transient increase in osmolarity of cells and lis follows the external osmotic pulse in such a way that lis remains hyperosmotic to cells at all times maintained by lateral $\mathrm{Na}^{+} / \mathrm{K}^{+}$ pump (Fig. 10e, f). 

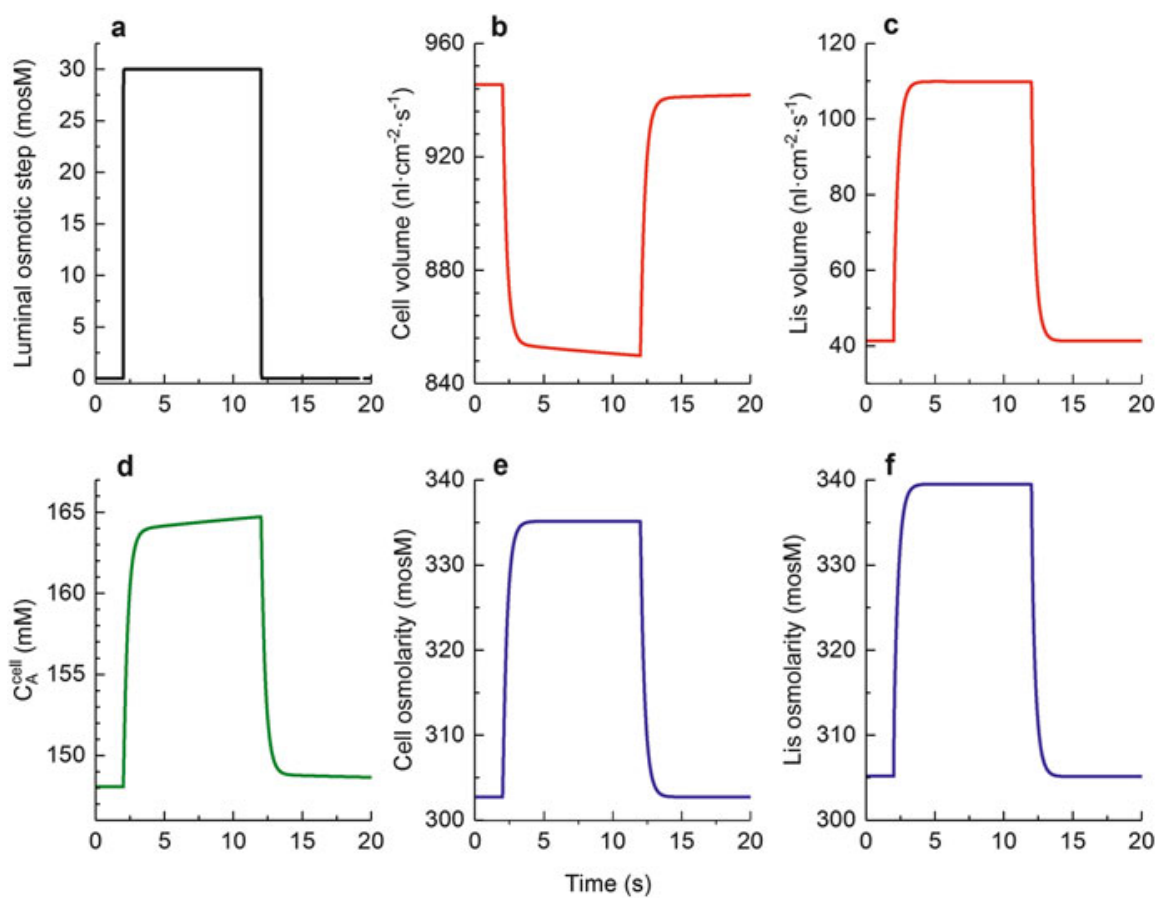

Fig. 10 (a-f) Time-dependent responses to reversible luminal osmotic step. (a) Pulse of 30-mosM of an electroneutral, non-permeable solute applied to outside (luminal) solution. (b, c) Time course of change in the two intraepithelial water volumes; cell volume decreases, while lis volume increases. (d) The loss of cell water results in concentration increase in the non-permeable negatively charged intracellular electrolyte with a time course similar to that of change in cell volume. (e,f) Cell and lis osmolarity increase. At all times is osmolarity of lis larger than osmolarity of cell

\subsection{Uphill Water Transport and Intraepithelial Water Fluxes}

In Fig. 11, a non-permeable electroneutral solute is added in steps of 5 mosM to the luminal compartment. The two examples are with and without $5 \mathrm{mM}$ glucose, respectively. In both cases, the relationship between water fluxes emerging from the lateral intercellular space and osmotic driving force is near-linear, displaying $\mathrm{x}$-axis intercepts of -27 and -37 mosM, respectively. Thus, the model reproduces "uphill" water transport as observed in proximal tubule of rat (Green et al. 1991) and mice (Schnermann et al. 1998) and generated by previous models of leaky epithelia (Weinstein and Stephenson 1981; Larsen et al. 2000, 2009). In the literature, an (apparent) osmotic permeability of the epithelium is calculated by:

$$
P_{f}^{e p i t}=\Delta J_{V}^{\text {trans }} /\left(\Delta \pi^{o} \cdot \bar{V}_{W}\right)
$$

where $\bar{V}_{W}=18.1 \mathrm{~cm}^{3} / \mathrm{mol}$ is the molar volume of water at $310 \mathrm{~K}$. From the slope of linear fits, $P_{f}^{\text {epit }}=680 \mu \mathrm{m} \mathrm{s}^{-1}$. This is significantly smaller than 


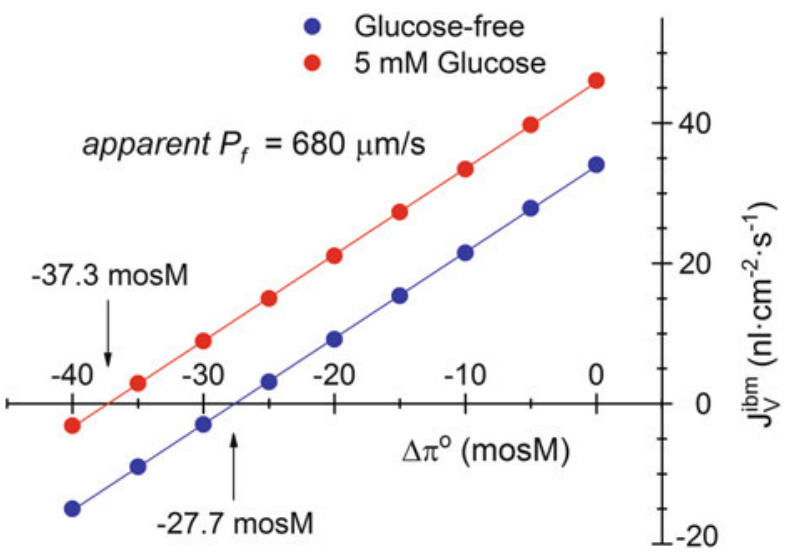

Fig. 11 The model epithelium transports water against an adverse osmotic gradient ("uphill"). A ramp of increasing outside concentration of a non-permeable electroneutral solute, $\Delta \pi^{\circ}$, was imposed on the model epithelium. The graph shows computed steady-state water fluxes emerging from the lateral intercellular space at each ramp step of 5 mosM. The enhanced water flux following addition of glucose owes to the coupling of $\mathrm{Na}^{+}$and glucose in apical SGLT2 which depolarizes the cell membranes. As a result, the $\mathrm{Na}^{+}$pumps in the lateral membrane are stimulated ("cross-talk") which directs an enhanced rate of transepithelial water uptake. Full lines are linear fits to computed points. The slope of the linear relationships denoted apparent $P_{f}$ has physical dimension of osmotic permeability. In the literature, it is used as measure of the osmotic permeability of the epithelium. As discussed in the text, its physical significance is ambiguous with no relationship to an osmotic permeability and should be abandoned

the rate-limiting osmotic permeabilities of apical entrance pathways, $P_{f}^{a m}+P_{f}^{t j}=$ $4,490+2,500=6,990 \mu \mathrm{m} \mathrm{s}^{-1}$. To explain this discrepancy, we will study nonstationary water fluxes between intraepithelial compartments by model computations, which cannot be studied by experiment. Figure 12 depicts the response of the apical membrane water flux to a 30 mosM pulse applied to luminal compartment. Prior to the pulse, the water flux is $21.3 \mathrm{~nL} \mathrm{~cm}^{-2} \mathrm{~s}^{-1}$. The "instantaneous" response is a fast reversal of the water flux to $-197 \mathrm{~nL} \mathrm{~cm}^{-2} \mathrm{~s}^{-1}$, driven by the imposed osmotic pulse, followed by relaxation toward an inward stationary flux of $35.1 \mathrm{~nL} \mathrm{~cm}^{-2} \mathrm{~s}^{-1}$ at the end of the pulse. While this inward water flux is energized by ATP hydrolysis at the lateral $\mathrm{Na}^{+} / \mathrm{K}^{+}$pumps, the time course of the relaxation depends on the compliance of the lateral plasma membrane; the more resilient the membrane, the longer it takes to achieve the new stationary flux, and for large $\mu^{l m}$, the water flux response is heavily attenuated as compared to the squared shape of the osmotic pulse. The standard compliance constant of the lateral membrane, $\mu^{l m}=2.5 \times 10^{-3} \mathrm{~Pa}^{-1}$, is taken from experiments on Necturus gallbladder (Spring and Hope 1978). As seen, this gives rise to transients of a few seconds duration. At the prevailing sampling rate of $300 \mathrm{~Hz}$, the amplitude of the "instantaneous" response is $21.3+197=218 \mathrm{~nL} \mathrm{~cm}^{-2} \mathrm{~s}^{-1}$ corresponding to an apparent osmotic permeability, $P_{f}^{a m}=4,037 \mu \mathrm{m} \mathrm{s}^{-1}$. This is significantly larger than the estimate 


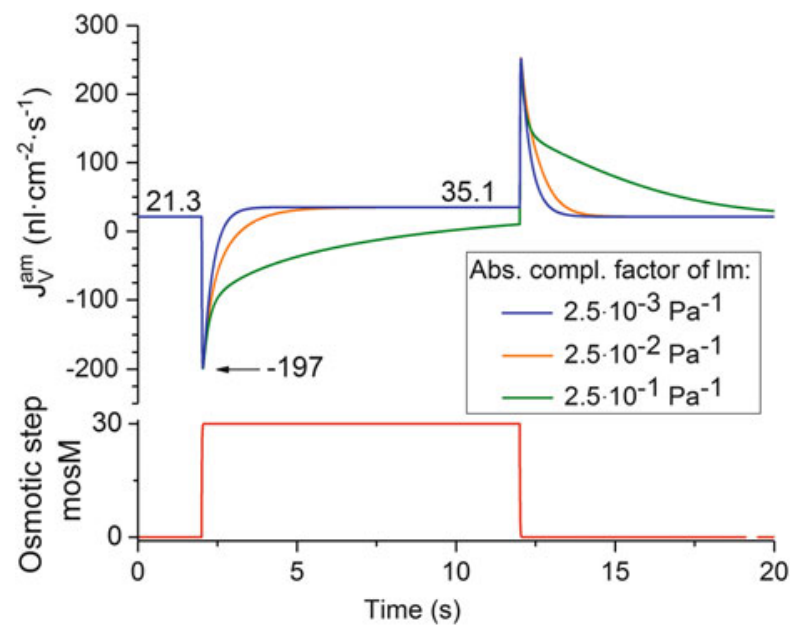

Fig. 12 Dependence of transient states of intraepithelial water fluxes on compliance factors of lateral intercellular membrane. Bottom panel applied luminal 10-s pulse of $30 \mathrm{mosM}$ of non-permeable electroneutral solute. Time constant of rise time, $\tau=0.01 \mathrm{~s}$, sampling rate $=300 \mathrm{~Hz}$. Upper panel, compliance factor-dependent relaxation of water flux redistribution between cells and lis with $\mathrm{Vol}^{l i s}=\operatorname{Vol}^{l i s,}{ }^{\text {ref }}\left[1+\mu^{l m}\left(p^{l i s}-p^{\text {cell }}\right)\right]$ (Eq. 18). Blue graph is given by standard input variables. Due to the very fast redirection of intraepithelial water fluxes, the peak response at the onset of the pulse of, $-197 \mathrm{~nL} \mathrm{~cm}{ }^{-2} \mathrm{~s}^{-1}$, is underestimating the apical membrane's water permeability. Thus, the amplitude of the "instantaneous" response is $-197-21.3=\sim 218 \mathrm{~nL} \mathrm{~cm}^{-2} \mathrm{~s}^{-1}$ corresponding to an apparent osmotic permeability of apical membrane, $P_{f}^{a m}=4,037 \mu \mathrm{m} \mathrm{s}^{-1}$, as compared to the true $P_{f}^{a m}=4,490 \mu \mathrm{m} \mathrm{s}^{-1}$

provided by the method of Fig. 11, and much closer to, but not identical with the model's permeability of, $P_{f}^{a m}=4,490 \mu \mathrm{m} \mathrm{s}^{-1}$. This is not due to the sampling rate of $300 \mathrm{~Hz}$ being too slow (not shown), but because the osmotic permeability of the "network" of epithelial membranes distributes "instantaneously" water fluxes between intraepithelial compartments. This is illustrated in Fig. 13a-d, where the analysis is extended for covering all intraepithelial water fluxes. Quasi-stationary states are achieved for all fluxes within the pulse length of $10 \mathrm{~s}$; the numbers given in the four panels verify consistency of intraepithelial fluxes.

\subsection{Isosmotic Transport}

The present study shows that a physiological variation of the rate of fluid absorption by proximal tubule of constant osmotic membrane permeabilities results in predictable variation in osmolarity of transported fluid. For example, an osmolarity of transported fluid of 316 mosM becomes 335 mosM when the rate of fluid absorption is increased by adding glucose to the external solutions (Figs. 2 and 4). Decreasing the osmotic permeability of the luminal membrane also increased the hyperosmolarity, e.g., from 316 to 359 mosM (Figs. 6 and 7). In vitro, the proximal 

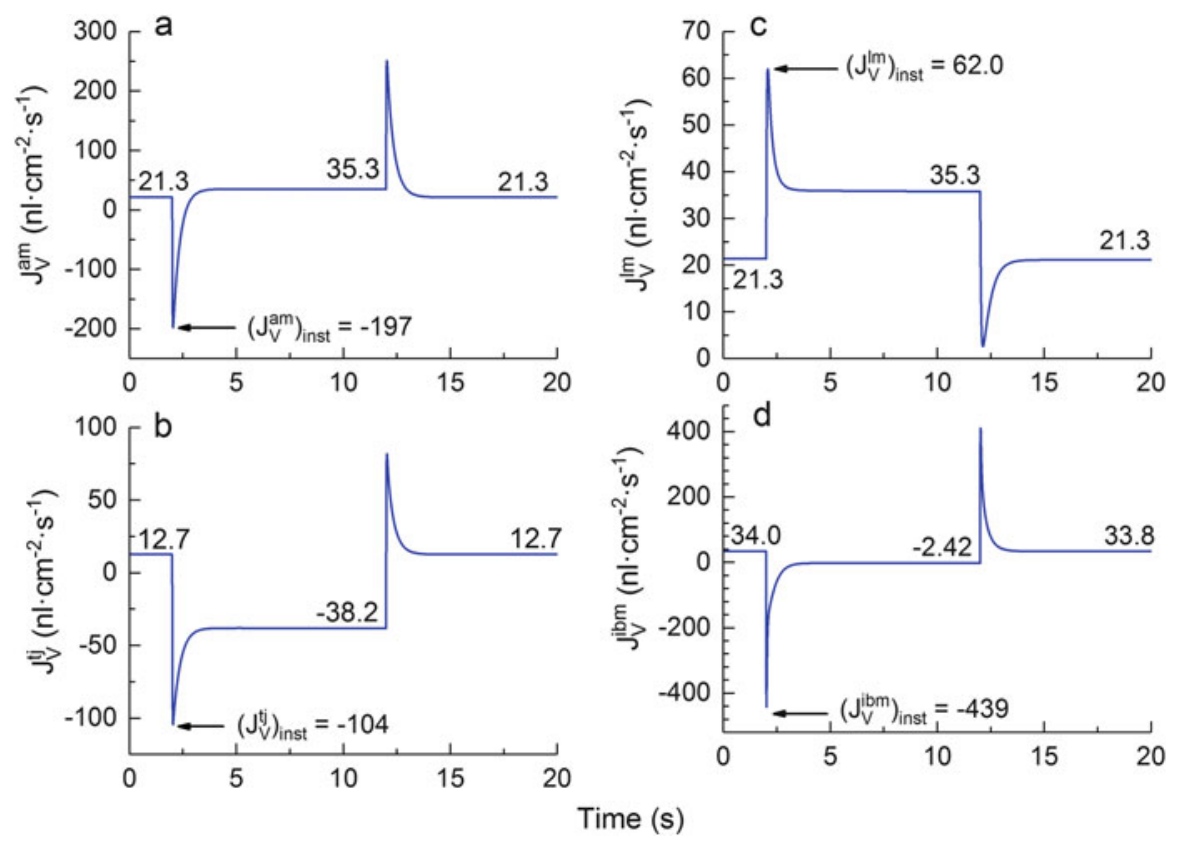

Fig. 13 (a-d) Response of intraepithelial water fluxes to luminaly applied 30-mosM pulse. The pulse applied is defined in Fig. 10a. (a) Water flux across apical membrane; graph is that of Fig. 10 with $\mu^{l m}=2.5 \times 10^{-3} \mathrm{~Pa}^{-1}$. (b) Water flux in tight junction is directed toward hyperosmotic luminal bath. In quasi-stationary state, $J_{V}^{t j}=-38.2 \mathrm{~nL} \mathrm{~cm}^{-2} \mathrm{~s}^{-1}$, illustrating that it is energized by the hyperosmotic pulse. (c) Water flux across plasma membrane lining the lateral intercellular space is positive from cell to lis. $J_{V}^{l m}$ added to the tight junction flux $\left(J_{V}^{t j}\right)$ leaves the epithelium across $i b m$ to the serosal bath. (d) Water flux across the intercellular basement membrane into serosal compartment. The small difference in water fluxes at $t=0 \mathrm{~s}$ and $t=20 \mathrm{~s}$, respectively, reflects that intraepithelial ion and volume redistributions are too slow for bringing the epithelium back to its initial steady state (details not shown)

tubule accomplishes isosmotic transport independent of the presence of glucose in luminal perfusion solution. Thus, the above computations show that our model cannot provide an isosmotic absorbate for a given set of osmotic permeabilities. This is an important finding because it indicates that isosmotic absorption is achieved by regulation at epithelial cell level. In an experimental study designed by Ussing of the mechanism of isosmotic transport by the small intestine, Nedergaard et al. (1999) observed that sodium ions are recirculated from the serosal solution via cells back into the lateral intercellular space, which suggested a mechanism for regulating the osmolarity of the transported fluid. In the small intestine (Larsen et al. 2002) and amphibian skin (Larsen et al. 2009), the recirculation pathway would be the 1Na:2Cl:1K cotransporter studied by Frizzell et al. (1979), Ferreira and Ferreira (1981), and Ussing (1985), respectively. In the heterocellular proximal tubule with absorption of $\mathrm{Na}^{+}, \mathrm{Cl}^{-}$, and $\mathrm{HCO}_{3}{ }^{-}$, one would expect that different segments handle recirculation by different cotransporters depending on whether $\mathrm{Cl}^{-}$or $\mathrm{HCO}_{3}^{-}$are transported together with $\mathrm{Na}^{+}$. For illustrating the 


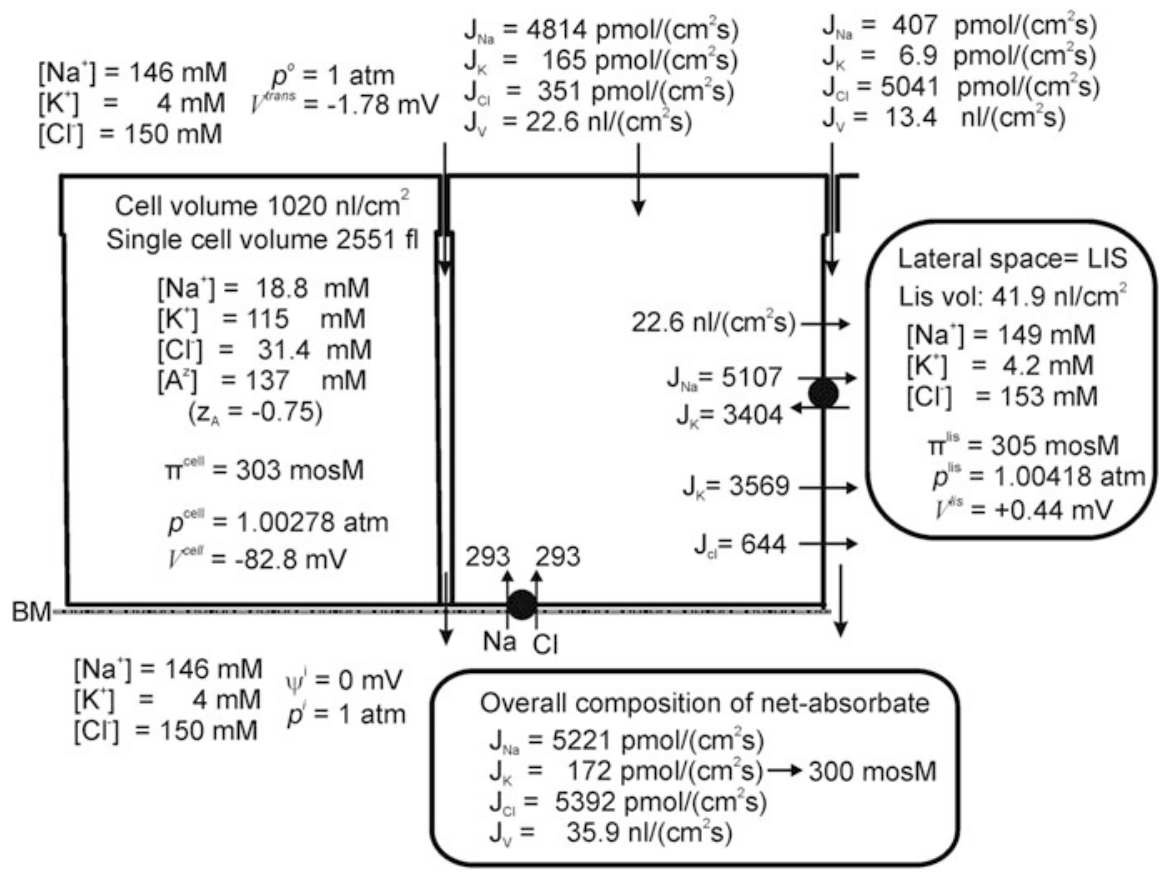

Fig. $14 \mathrm{The}^{+}{ }^{+}$recirculation theory applied to the kidney proximal tubule. Model solution illustrating how truly isosmotic transport is achieved by recirculating $\mathrm{Na}^{+}$and $\mathrm{Cl}^{-}$from the serosal compartment back into the lateral intercellular coupling compartment energized by lateral $3 \mathrm{Na}^{+} /$ $2 \mathrm{~K}^{+}$-pumps. Independent variables of all membrane pathways are similar to those used in computations of Fig. 2 in which the serosal $1 \mathrm{Na}: 1 \mathrm{Cl}$ cotransporter is quiescent. Turning on regulated $1 \mathrm{Na}: 1 \mathrm{Cl}$ cotransport corrected the hyperosmotic absorbate emerging from the lateral space to an overall osmolarity of the absorbate of $300 \mathrm{mosM}$. It should be noted that the $1 \mathrm{Na}: 1 \mathrm{Cl}$ cotransporter is considered here just for the purpose of illustration

significance of regulated ion recirculation in the minimalistic model of the proximal tubule, we introduced a $1 \mathrm{Na}: 1 \mathrm{Cl}$ cotransporter of the serosal membrane and adjusted the fluxes carried by this transporter until an overall isosmotic fluid transport was achieved. The result is shown in Fig. 14. It can be seen that a recirculation of $J_{\mathrm{NaCl}}^{s m}=$ -293 pmol $\mathrm{cm}^{-2} \mathrm{~s}^{-1}$ results in truly isosmotic transport of 300 mosM; this is associated with an increase of $C_{N a}^{\text {cell }}$ from 16.2 to $18.8 \mathrm{mM}$ and an increase of $C_{C l}^{\text {cell }}$ from 21.8 to $31.4 \mathrm{mM}$. The concomitant increase in active $\mathrm{Na}^{+}$pump flux from 4,816 to $5,107 \mathrm{pmol} \mathrm{cm}^{-2} \mathrm{~s}^{-1}$ indicates that the extra metabolic load of generating truly isosmotic transport would be modest, $100(5,107-4,816) / 4,816=6.0 \%$, compared to the results of Fig. 2 obtained with no recirculation. 


\section{Discussion}

Our previously published analytical model of transporting epithelia (Larsen et al. 2002) is here extended for analyzing transient states evoked by perturbing independent variables for simulating commonly applied experimental protocols. This has allowed us to deal with time-dependent dynamic interactions of ion and water fluxes through the epithelium and, for the first time, between subepithelial compartments. The updated model also contains equations for the $\mathrm{Na}^{+} / \mathrm{K}^{+}$pump and the $\mathrm{Na}^{+}-$ glucose transporter (SGLT2) with new equations for these transport systems' contribution to the electrical conductance of the plasma membranes. The model was shown to be quite sufficient for giving answers to a number of pertinent problems in kidney physiology that presupposes quantitative biophysical analysis. The check on these points was provided by comparing published experimental observations with predictions given by the model.

\subsection{The Coupling Between Active Sodium Transport and Fluid Uptake}

The model reproduces a large number of observations based on a physiologically plausible set of input variables such as intracellular ion composition, membrane potentials and resistances, cell volumes, and transepithelial fluxes of water and ions all in agreement with proximal convoluted tubule in situ and microperfused tubule segments (Figs. 2 and 4). Ion composition, hydrostatic pressure, and volume of the lateral intercellular space, inaccessible to measurements in a transporting epithelium, are obtained at any physiological condition. The convection-electrodiffusion equation for tight junction transport provides basis for discussion of leak fluxes associated the reabsorption of the major fraction of the ultrafiltrate. Interestingly, based upon the convection-electrodiffusion equation (Eq. 6), calculations shown in Figs. 4 and 6 and in Table 1 predict as a novel result that passive back leaks would be prevented by solvent drag in tight junctions in the initial segment of proximal tubule, where the electrochemical driving force otherwise would return a component of the $\mathrm{Na}^{+}$flux to the tubule lumen.

This seems to be a suitable point at which to emphasize that absorption by proximal tubule of $\mathrm{K}^{+}$requires active uptake mechanism, here given by Eq. (2a), because paracellular solvent drag turned out to be quite insufficient, see Sect. 3.1, underscoring the importance of the experimental study by Wilson et al. (1997). By choosing appropriate value of the intrinsic parameter, $K^{\mathrm{NaK} 2 \mathrm{Cl} \text {, am }}$ of Eq. (2a) we could direct the overall transepithelial $\mathrm{K}^{+}$absorption so that the potassium ion concentration of the absorbate becoming close to that of the interstitial fluid. [Results of such a use of the model are independent of the molecular mechanism of active $\mathrm{K}^{+}$ uptake]. Thus, governed by the same value of $\mathrm{K}^{\mathrm{NaK2Cl} \text {, am }}$ in Figs. 2 and 4, the $\mathrm{K}^{+}$ concentration of the absorbate calculates to be 5.2 and $4.1 \mathrm{mM}$, respectively. With a 
fluid absorption rate of 120 1/day by proximal tubule of human kidney the extracellular $\mathrm{K}^{+}$concentration could possibly not be maintained within physiological values unless the $\left[\mathrm{K}^{+}\right]$of the absorbate is regulated at epithelial cell level to be within a range not much different from the physiological range stated to be between 3.8 and $5.0 \mathrm{mM}$ (Hall 2016). By emphasizing the necessity of active $\mathrm{K}^{+}$absorption by proximal tubule and the significance of achieving a $\left[\mathrm{K}^{+}\right]$of the absorbate that is not much different from that of the serosal fluid our analysis has pointed out two important questions for future studies: (1) identification of the molecular mechanism of active transport across the apical membrane, and (2) disclosure of the nature of coordination of the rate of fluid absorption and the flux of $\mathrm{K}^{+}$absorption, respectively, for securing near-extracellular $\left[\mathrm{K}^{+}\right]$of the absorbate.

The model predicts the well-established stimulation of $\mathrm{Na}^{+}$- and fluid absorption by glucose (Figs. 4 and 5). Of particular interest, the new kinetics- and conductanceequations for SGLT2 (Eqs. 3a, 3c) predict the membrane depolarization and decrease in apical membrane resistance caused by glucose absorption, as observed in a microelectrode study by Frömter (1982). With reference to Fig. 4, computed for $5 \mathrm{mM}$ external glucose, the reversal potential of the SGLT2 transporter is given by the expression (cf. Methods),

$$
\begin{aligned}
E_{\text {rev }}^{G l u \cdot N a, a m} & =\frac{R T}{F} \ln \frac{C_{G l u}^{o} \cdot C_{N a^{+}}^{o}}{C_{G l u}^{c e l l} \cdot C_{N a^{+}}^{c e l l}} \\
& =10^{3} \times \frac{8.31 \cdot 310}{96485} \ln \frac{5 \cdot 146}{11.8 \cdot 28.2} \\
& =21.0 \mathrm{mV}
\end{aligned}
$$

This is $100 \mathrm{mV}$ above the membrane potential of $-79 \mathrm{mV}$ indicating that our conclusion of glucose absorption by the reversible SGLT2 is robust. It is a new and physiologically significant finding of our study that the voltage dependence of the active $\mathrm{Na}^{+}$flux (Eq. 4a) predicts an overlooked "cross-talk" mechanism between apical rheogenic $\mathrm{Na}^{+}$uptake and active $\mathrm{Na}^{+} / \mathrm{K}^{+}$pump fluxes across the lateral membrane. The physiological implication of this mechanism is indicated by the secondary effect on rate of fluid uptake and a higher osmolarity of the fluid exiting the epithelium via the lateral intercellular space (Fig. 4).

\subsection{Eliminating the Osmotic Permeability of Apical Membrane}

An intriguing result was obtained when a simulation of aquaporin knock-out showed that water uptake at transepithelial osmotic equilibrium is not significantly changed after elimination of the osmotic permeability of the apical membrane: $J_{V}=34.0 \mathrm{~nL} \mathrm{~cm}^{-2} \mathrm{~s}^{-1}$ for $P_{f}^{a m}=4,490 \mu \mathrm{m} \mathrm{s}^{-1}$ and $J_{V}=35.4 \mathrm{~nL} \mathrm{~cm}^{-2} \mathrm{~s}^{-1}$ for 
$P_{f}^{a m}=0.449 \mu \mathrm{m} \mathrm{s}^{-1}$, respectively (Figs. 2 and 6). This maneuver effectively blocked the translateral water flux and forced the water absorption to be entirely paracellular (Fig. 6). This response was analyzed in detail by following the development of nonstationary states toward the new steady state. By predicting an increase in the osmolarity of the lateral intercellular space, the analysis provided the biophysical mechanism for the large increase in osmolarity of the absorbate (Fig. 7). The experimental study by Schnermann et al. (1998) showed that AQP-1-null mice exhibited a tubular fluid absorption that is $50 \%$ of that of AQP-1(+/+) mice. In our analysis of this finding, we showed that the rate of fluid absorption is given by the rate at which sodium ions are pumped into the lateral intercellular space, independent of the pathway taken by water (Figs. 8 and 9). Therefore, we can conclude that the observed significant decrease in rate of fluid absorption in AQP-1(-/-) mice has to be ascribed solely to the authors' concomitantly reported reduction in active $\mathrm{Na}^{+}$absorption. The computed relationship between transepithelial water uptake and active flux of sodium ions (Fig. 9) is a general and fundamental feature of fluid transporting epithelia.

The general applicability of the present study is underscored by pointing out that our analysis eliminates the paradox discussed by Wittekindt and Dietl (2019) that aquaporins in the lung facilitate osmotic water transport, whereas their contribution to water fluxes at near-isosmotic conditions was concluded "elusive." Our analysis of this problem leads to the conclusion that also in the lung are aquaporins of physiological importance for isosmotic transport with the rate of water transport given by the active sodium flux, that is, not by expression of aquaporins. This applies to AQP-1(-/-) engineered lung epithelia as well where the water flow is redirected to the paracellular pathway at a rate given by the active $\mathrm{Na}^{+}$flux (conf. Figs. 2 and 6).

\subsection{Transepithelial Osmotic Permeability Versus Osmotic Permeability of Individual Membranes}

The substantial discrepancy between the osmotic permeability of the epithelium obtained by transepithelial osmotic step experiments and the significantly larger experimentally estimated osmotic permeabilities of individual plasma membranes (Carpi-Medina et al. 1984; Gonzáles et al. 1984; Schafer et al. 1978) was characterized by Weinstein (2013) as "one of the confusing features" of epithelia specialized for isosmotic transport. Our analysis provided the mechanistic explanation for this "confusing feature" by revealing how lateral $\mathrm{Na}^{+} / \mathrm{K}^{+}$pumps on a time scale of about $1 \mathrm{~s}$ energize redistribution of water flows between intraepithelial compartments that in the end results in relatively small changes in transepithelial water fluxes and uphill water transport across the epithelium (Figs. 11, 12 and 13). This result illustrates the advantage of our dynamic model over and above the steady-state model of Weinstein (2013) which requires a hypotonic luminal space for generating an absorbed fluid that is "isosmotic to plasma." Our computational analytical method providing timedependent states of physical variables enabled us to study the time course of 
intraepithelial water redistributions that result from an imposed external osmotic pulse. Obviously, a "transepithelial osmotic permeability" calculated from this type of experimental protocol is inadequate for functional characterization of the transporting epithelium (Figs. 9 and 12). Furthermore, the result of our analysis shows that Weinstein's concept of "intraepithelial solute polarization" cannot be ascribed physical significance. In conclusion, it is a result of significant physiological implications that the osmotic permeability of the whole epithelium $P_{f}^{\text {epit }}$ has ambiguous biophysical meaning and should be abandoned in studies of water fluxes across intact epithelia.

\subsection{Truly Isosmotic Transport}

In the standing gradient theory of isosmotic transport by Diamond and Bossert (1967), sodium pumps are located in the closed apical end of the lateral intercellular space. It was hypothesized that for a particular set of independent variables such as active pumping rate, diffusion coefficients in lis of unstirred fluid, and physical dimensions of the space, this model would have capacity to generate isosmotic transport. The theory directed fresh approaches to the problem of solute-coupled fluid transport and broadened the field by including epithelia of a larger number of animal species adapted to a variety of habitats as reviewed in Berridge and Oschmann (1972). The theory is now abandoned because pumps are uniformly distributed in the lateral membrane or concentrated near the basal end, tight junctions are permeable to both ions and water, and the lateral space cannot be assumed unstirred. Importantly, however, Diamond and Bossert's theoretical approach gave rise to a clear formulation of the fundamental problem of isosmotic transport. In the authors' own words (loc. cit. page 2077), "two forces are responsible for carrying solute out the open mouth of the system: the diffusion of solute down its concentration gradient, and the sweeping effect of water flow upon solute. Any factor that increases the relative importance of diffusion will make the emergent fluid more hypertonic, while factors increasing the relative importance of water flow are associated with a more nearly isotonic emergent fluid."

Mathematical models of today are significantly different from the Diamond and Bossert model; the fluid of the lateral intercellular space is assumed well stirred, tight junctions are ion- and water permeable, a basement membrane is separating lis and serosal compartment, and hydrostatic pressures and membrane potentials constitute driving forces for water and ion flows. Furthermore, in our treatment of convection-electrodiffusion at the interfaces limiting the lateral intercellular space from outside and inside compartments, respectively, we introduced an expanded version of Hertz' equation (Larsen et al. 2002). Nevertheless, in general terms, our computations underscored the above conclusion of the Diamond-Bossert paper.

A study applying the pre-steady-state theorem (Sten-Knudsen and Ussing 1981) for separating paracellular and transcellular radioactive $\mathrm{Na}^{+}$fluxes in small intestine 
indicated recirculation of sodium ions from serosal solution bath back into lateral space via the transporting epithelial cells (Nedergaard et al. 1999). Our subsequent theoretical analysis (Larsen et al. 2002) indicated that the fairly large recirculation fluxes of the above study follow logically from the relatively small osmotic permeability of small intestine. The present study indicates that in the highly water permeable proximal tubule the putative $\mathrm{Na}^{+}$recirculation flux necessary for isosmotic transport would be small and probably too small for being measured. This prediction focuses future research on the precise nature and operation of the serosal $\mathrm{Na}^{+}$cotransporters that may mediate $\mathrm{Na}^{+}$recirculation in the different segments of proximal tubule.

\section{Additional Information}

\section{Competing Interests}

None declared.

\section{Author Contributions}

EHL contributed to the conception of the work. JNS developed the FORTRAN program including the numerical methods. EHL provided mathematical equations, performed most of the computations, and wrote the first draft of the manuscript that was further edited by both authors. Both authors have approved the final version of the manuscript and agree to be accountable for all aspects of the work and qualify for authorship. No one else qualify for authorship.

\section{Funding}

This work was supported by grant CF17-0186 from the Carlsberg Foundation.

\section{Appendix 1: Nomenclature}

See also overview in Fig. $1 b$.

\begin{tabular}{l|l}
\hline Variables or constants and their definition & Symbol \\
\hline $\begin{array}{l}\text { Concentration of } j\left(\mathrm{Na}^{+}, \mathrm{K}^{+}, \mathrm{Cl}^{-}, \mathrm{A}^{-}, \text {or } \text { glucose }\right) \text { in compartment comp }(o, \text { cell, }, \\
\text { lis, or } i)\end{array}$ & $C_{j}^{\text {comp }}$ \\
\hline Osmolarity of compartment indicated by superscript $(o$, cell, lis, or $i)$ & $\pi^{\text {comp }}$ \\
\hline Hydrostatic pressure of compartment indicated $(o$, cell, lis, or $i)$ & $p^{\text {comp }}$ \\
\hline Electrical potential of compartment indicated $(o$, cell, lis, or $i)$ with $\psi^{i} \equiv 0$ & $\psi^{\text {comp }}$ \\
\hline Transepithelial potential difference, $\psi^{o}-\psi^{i}$ & $V^{\text {trans }}$ \\
\hline Electrical potential difference between $o$ and cell, $\psi^{o}-\psi^{\text {cell }}$ & $V^{\text {am }}$ \\
\hline Electrical potential difference between cell and $l i s, \psi^{\text {cell }}-\psi^{l i s}$ & $V^{l m}$ \\
\hline Electrical potential difference between cell and $i, \psi^{\text {cell }}-\psi^{i}$ & $V^{\text {sm }}$ \\
\hline & (continued)
\end{tabular}




\begin{tabular}{|c|c|}
\hline Variables or constants and their definition & Symbol \\
\hline Passive permeability of $j$ in membrane $m(a m, l m, s m, t j, i b m)$ & $P_{j}^{m}$ \\
\hline Reflection coefficient of $j\left(\mathrm{Na}^{+}, \mathrm{K}^{+}, \mathrm{Cl}^{-}\right.$, glucose $)$in $m(t j, i b m)$ & $\sigma_{j}^{m}$ \\
\hline Flux of $j\left(=\mathrm{Na}^{+}, \mathrm{K}^{+}, \mathrm{Cl}^{-}\right.$, glucose $)$across $m(a m, l m, s m, t j, i b m)$ & $J_{j}^{m}$ \\
\hline Electrical current carried by $j\left(\mathrm{Na}^{+}, \mathrm{K}^{+}, \mathrm{Cl}^{-}\right)$across $m(a m, l m, s m, t j, i b m)$ & $I_{j}^{m}$ \\
\hline Integral ion $(j)$ conductance of membrane $m$ & $G_{j}^{m}$ \\
\hline Water volume flux across $m(a m, l m, s m, t j, i b m)$ & $J_{V}^{m}$ \\
\hline Hydraulic conductance of membrane $m(\mathrm{am}, \mathrm{lm}, \mathrm{sm}, \mathrm{tj}, \mathrm{ibm})$ & $L^{m}$ \\
\hline Osmotic permeability of $m(a m, l m, s m, t j, i b m)$ & $P_{f}^{m}$ \\
\hline Relative compliance constant of membrane $m(\mathrm{am}, \mathrm{lm}, \mathrm{sm})$ & $\mu^{m}$ \\
\hline Absolute compliance constant of $l m$ & $\bar{\mu}^{l m}$ \\
\hline Empirical constant of $1 \mathrm{Na}: 1 \mathrm{~K}: 2 \mathrm{Cl}$ cotransporter of membrane $m$ & $K^{\mathrm{NaK} 2 \mathrm{Cl}, \mathrm{m}}$ \\
\hline Empirical constant of $1 \mathrm{Na}: 1 \mathrm{Cl}$ cotransporter of membrane $m$ & $K^{\mathrm{NaCl}, \mathrm{m}}$ \\
\hline Apparent dissociation constants of $\mathrm{Na}^{+}$binding of $\mathrm{Na}^{+} / \mathrm{K}^{+}$pump at $l m$ & $K_{N a^{+}}^{\text {pump }, l m}$ \\
\hline Apparent dissociation constants of $\mathrm{K}^{+}$binding of $\mathrm{Na}^{+} / \mathrm{K}^{+}$pump at $l m$ & $K_{K^{+}}^{\text {pump }, l m}$ \\
\hline Turnover constant of $\mathrm{Na}^{+}$: glucose transporter at $a m$ & $P^{G l u \cdot N a^{+}}$ \\
\hline Empirical apparent dissociation constant of $\mathrm{Na}^{+}$:glucose transporter at am & $K_{G l u}^{G l u \cdot N a}$ \\
\hline $\begin{array}{l}\text { Empirical apparent dissociation constant for glucose of } \mathrm{Na}^{+} \text {:glucose transporter } \\
\text { at } \mathrm{am}\end{array}$ & $\mathrm{K}_{\mathrm{Na}}^{\mathrm{Glu}} \cdot \mathrm{Na}$ \\
\hline Maximum turnover of glucose exchanger at $l m$ & $J_{G l u}^{\max , l m}$ \\
\hline App dissociation const. of symmetrical carrier at $l m$ & $K_{G l u}^{l m}$ \\
\hline Turnover constant of $\mathrm{Na}^{+}$: glucose transporter at $a m$ & $P^{G l u \cdot N a^{+}}$ \\
\hline Temperature in $\mathrm{K}$ & $T$ \\
\hline Faraday & $F$ \\
\hline Universal gas constant & $R$ \\
\hline
\end{tabular}

\section{Appendix 2: Independent Variables}

\begin{tabular}{l|l|l|l}
\hline Name & Symbol & Value & MKSA unit \\
\hline Hydraulic conductance of $a m$ & $L^{a m}$ & $3.1370 \mathrm{~d}-11$ & $\mathrm{~m}^{3} \mathrm{~s}^{-1} \mathrm{~N}^{-1}$ \\
\hline Hydraulic conductance of $s m$ & $L^{s m}$ & $3.5000 \mathrm{~d}-14$ & $\mathrm{~m}^{3} \mathrm{~s}^{-1} \mathrm{~N}^{-1}$ \\
\hline Hydraulic conductance of $l m$ & $L^{l m}$ & $3.4980 \mathrm{~d}-11$ & $\mathrm{~m}^{3} \mathrm{~s}^{-1} \mathrm{~N}^{-1}$ \\
\hline Hydraulic conductance of $t j$ & $L^{t j}$ & $3.1370 \mathrm{~d}-11$ & $\mathrm{~m}^{3} \mathrm{~s}^{-1} \mathrm{~N}^{-1}$ \\
\hline Hydraulic conductance of $i b m$ & $L^{i b m}$ & $2.3100 \mathrm{~d}-07$ & $\mathrm{~m}^{3} \mathrm{~s}^{-1} \mathrm{~N}^{-1}$ \\
\hline $\mathrm{Na}^{+}$concentration of outside compartment & $C_{N a}^{o}$ & 146 & $\mathrm{~mol} \mathrm{~m}^{-3}$ \\
\hline $\mathrm{K}^{+}$concentration of outside compartment & $C_{K}^{o}$ & 4 & $\mathrm{~mol} \mathrm{~m}^{-3}$ \\
\hline $\mathrm{Cl}^{-}$concentration of outside compartment & $C_{C l}^{o}$ & 150 & $\mathrm{~mol} \mathrm{~m}^{-3}$ \\
\hline $\begin{array}{l}\text { Concentration of non-diffusible solute of } \\
\text { outside compartment }\end{array}$ & $C_{S}^{o}$ & $\begin{array}{l}\text { Protocol } \\
\text { dependent }\end{array}$ & $\mathrm{mol} \mathrm{m}^{-3}$ \\
\hline $\begin{array}{l}\text { Glucose concentration of outside } \\
\text { compartment }\end{array}$ & $C_{g l u}^{o}$ & 0,3 or 5 & $\mathrm{~mol} \mathrm{~m}^{-3}$ \\
\hline
\end{tabular}




\begin{tabular}{|c|c|c|c|}
\hline Name & Symbol & Value & MKSA unit \\
\hline $\mathrm{Na}^{+}$concentration of inside compartment & $C_{N a}^{i}$ & 146 & $\mathrm{~mol} \mathrm{~m}^{-3}$ \\
\hline $\mathrm{K}^{+}$concentration of inside compartment & $C_{K}^{i}$ & 4 & $\mathrm{~mol} \mathrm{~m}^{-3}$ \\
\hline $\mathrm{Cl}^{-}$concentration of inside compartment & $C_{C l}^{i}$ & 150 & $\mathrm{~mol} \mathrm{~m}^{-3}$ \\
\hline $\begin{array}{l}\text { Concentration of non-diffusible solute of } \\
\text { inside comp. }\end{array}$ & $C_{S}^{i}$ & 0 & $\mathrm{~mol} \mathrm{~m}^{-3}$ \\
\hline Glucose concentration of inside compartment & $C_{g l u}^{i}$ & 0,3 , or 5 & $\mathrm{~mol} \mathrm{~m}^{-3}$ \\
\hline $\mathrm{Na}^{+}$GHK permeability of $\mathrm{am}$ & $P_{\mathrm{Na}}^{a m}$ & $0.100 \mathrm{~d}-6$ & $\mathrm{~m} \mathrm{~s}^{-1}$ \\
\hline $\mathrm{K}^{+}$GHK permeability of $\mathrm{am}$ & $P_{K}^{a m}$ & $0.274 d-12$ & $\mathrm{~m} \mathrm{~s}^{-1}$ \\
\hline $\mathrm{Cl}^{-}$GHK permeability of $\mathrm{am}$ & $P_{C l}^{a m}$ & $0.160 \mathrm{~d}-11$ & $\mathrm{~m} \mathrm{~s}^{-1}$ \\
\hline $\mathrm{Na}^{+}$GHK permeability of $s m$ & $P_{\mathrm{Na}}^{s m}$ & $0.100 \mathrm{~d}-11$ & $\mathrm{~m} \mathrm{~s}^{-1}$ \\
\hline $\mathrm{K}^{+}$GHK permeability of $s m$ & $P_{K}^{s m}$ & $0.100 \mathrm{~d}-11$ & $\mathrm{~m} \mathrm{~s}^{-1}$ \\
\hline $\mathrm{Cl}^{-}$GHK permeability of $s m$ & $P_{C l}^{s m}$ & $0.100 \mathrm{~d}-11$ & $\mathrm{~m} \mathrm{~s}^{-1}$ \\
\hline $\mathrm{Na}^{+}$GHK permeability of $\mathrm{lm}$ & $P_{N a}^{l m}$ & $0.300 \mathrm{~d}-12$ & $\mathrm{~m} \mathrm{~s}^{-1}$ \\
\hline $\mathrm{K}^{+}$GHK permeability of $l m$ & $P_{K}^{l m}$ & $0.120 \mathrm{~d}-6$ & $\mathrm{~m} \mathrm{~s}^{-1}$ \\
\hline $\mathrm{Cl}^{-}$GHK permeability of $\mathrm{lm}$ & $P_{C l}^{l m}$ & $0.800 \mathrm{~d}-7$ & $\mathrm{~m} \mathrm{~s}^{-1}$ \\
\hline $\mathrm{Na}^{+}$GHK permeability of $t j$ & $P_{N a}^{t j}$ & $0.125 d-6$ & $\mathrm{~m} \mathrm{~s}^{-1}$ \\
\hline $\mathrm{K}^{+}$GHK permeability of $t j$ & $P_{K}^{t j}$ & $0.180 \mathrm{~d}-6$ & $\mathrm{~m} \mathrm{~s}^{-1}$ \\
\hline $\mathrm{Cl}^{-}$GHK permeability of $t j$ & $P_{C l}^{t j}$ & $0.400 \mathrm{~d}-5$ & $\mathrm{~m} \mathrm{~s}^{-1}$ \\
\hline Glucose permeability of $t j$ & $P_{g l u}^{i b m}$ & $0.950 \mathrm{~d}-8$ & $\mathrm{~m} \mathrm{~s}^{-1}$ \\
\hline $\mathrm{Na}^{+}$GHK permeability of $i b m$ & $P_{N a}^{i b m}$ & $0.750 \mathrm{~d}-6$ & $\mathrm{~m} \mathrm{~s}^{-1}$ \\
\hline $\mathrm{K}^{+}$GHK permeability of $i b m$ & $P_{K}^{i b m}$ & $0.110 \mathrm{~d}-5$ & $\mathrm{~m} \mathrm{~s}^{-1}$ \\
\hline $\mathrm{Cl}^{-}$GHK permeability of $\mathrm{ibm}$ & $P_{C l}^{i b m}$ & $0.159 \mathrm{~d}-4$ & $\mathrm{~m} \mathrm{~s}^{-1}$ \\
\hline Glucose permeability if $i b m$ & $P_{g l u}^{i b m}$ & $0.350 \mathrm{~d}-5$ & $\mathrm{~m} \mathrm{~s}^{-1}$ \\
\hline $1 \mathrm{Na}: 1 \mathrm{~K}: 2 \mathrm{Cl}$ co-transporter constant of $a m$ & $K^{\mathrm{NaK} 2 \mathrm{Cl}, \mathrm{am}}$ & $0.150 \mathrm{~d}-12$ & $\mathrm{~m}^{10} \mathrm{~s}^{-1} \mathrm{~mol}^{-3}$ \\
\hline $1 \mathrm{Na}: 1 \mathrm{Cl}$ co-transporter constant of am & $K^{\mathrm{NaCl}, \mathrm{am}}$ & $0.100 \mathrm{~d}-10$ & $\mathrm{~m}^{4} \mathrm{~s}^{-1} \mathrm{~mol}^{-1}$ \\
\hline Turnover constant of lateral $3 \mathrm{Na}^{+} / 2 \mathrm{~K}^{+}$pump & $P_{\mathrm{Na}^{+}, \mathrm{K}^{+}}^{\text {pump } l m}$ & $0.100 \mathrm{~d}-2$ & $\mathrm{~mol} \mathrm{~s}^{-1} \mathrm{~m}^{-2}$ \\
\hline Electromotive force of the $3 \mathrm{Na}^{+} / 2 \mathrm{~K}^{+}$pump & $E^{\text {pump }}$ & 0.2 & Volt \\
\hline $\begin{array}{l}\text { Apparent dissociation constants of } \mathrm{Na}^{+} \\
\text {binding }\end{array}$ & $K_{\mathrm{Na}^{+}}^{\text {pump }, \mathrm{lm}}$ & $3.40 \mathrm{~d} 0$ & $\mathrm{~mol} \mathrm{~m}^{-3}$ \\
\hline $\begin{array}{l}\text { Apparent dissociation constants of } \mathrm{K}^{+} \\
\text {binding }\end{array}$ & $K_{K^{+}}^{\text {pump }, l m}$ & $0.75 \mathrm{~d} 0$ & $\mathrm{~mol} \mathrm{~m}^{-3}$ \\
\hline $\begin{array}{l}\text { Turnover constant of } \mathrm{Na}^{+} \text {:glucose transporter } \\
\text { of } a m\end{array}$ & $P^{G l u \cdot N a^{+}}$ & $1.6 \mathrm{~d}-8$ & $\mathrm{~mol} \mathrm{~s}^{-1} \mathrm{~m}^{-2}$ \\
\hline Apparent dissociation constant for $\mathrm{Na}^{+}$ & $K_{G l u}^{G l u \cdot N a}$ & $5 . \mathrm{d} 0$ & $\mathrm{~mol} \mathrm{~m}^{-3}$ \\
\hline Apparent dissociation constant for glucose & $K_{\mathrm{Na}^{+}}^{\mathrm{Glu} \cdot \mathrm{Na}}$ & $0.25 \mathrm{~d} 2$ & $\mathrm{~mol} \mathrm{~m}^{-3}$ \\
\hline $\begin{array}{l}\text { Maximum turnover of glucose exchanger at } \\
\operatorname{lm}\end{array}$ & $J_{G l u}^{\max , l m}$ & $2.0 \mathrm{~d}-4$ & $\mathrm{~mol} \mathrm{~s}^{-1} \mathrm{~m}^{-2}$ \\
\hline $\begin{array}{l}\text { App dissociation const. of symmetry. carrier } \\
\text { at } l m\end{array}$ & $K_{G l u}^{l m}$ & $5.0 \mathrm{~d} 1$ & $\mathrm{~mol} \mathrm{~m}^{-3}$ \\
\hline Hydrostatic pressure of outside compartment & $p^{o}$ & $1.01325 \mathrm{e} 5$ & $\mathrm{~Pa}$ \\
\hline
\end{tabular}




\begin{tabular}{l|l|l|l}
\hline Name & Symbol & Value & MKSA unit \\
\hline Hydrostatic pressure of inside compartment & $p^{i}$ & $1.01325 \mathrm{e} 5$ & Pa \\
\hline Electrical potential of inside compartment & $\psi^{i}$ & 0 & Volt \\
\hline $\begin{array}{l}\text { Mean valence of nondiffusible intracellular } \\
\text { anions }\end{array}$ & $z_{A}$ & -0.75 & \\
\hline $\mathrm{Na}^{+}$reflection coefficient of $t j$ & $\sigma_{N a}^{t j}$ & 0.70 & \\
\hline $\mathrm{K}^{+}$reflection coefficient of $t j$ & $\sigma_{K}^{t j}$ & 0.70 & \\
\hline $\mathrm{Cl}^{-}$reflection coefficient of $t j$ & $\sigma_{C l}^{t j}$ & 0.45 & \\
\hline $\mathrm{Glucose}^{i j}$ & $\sigma_{G l u}^{j}$ & 0.80 & \\
\hline $\mathrm{Na}^{+}$reflection coefficient of $t j$ & $\sigma_{N a}^{i b m}$ & 0.03 & \\
\hline $\mathrm{K}^{+}$reflection coefficient of $i b m$ & $\sigma_{K}^{i b m}$ & 0.03 & \\
\hline $\mathrm{Cl}^{-}$reflection coefficient of $i b m$ & $\sigma_{C l}^{i b m}$ & 0.03 & $\mathrm{~K}$ \\
\hline Glucose reflection coefficient of $i b m$ & $\sigma_{G l u}^{i b m}$ & 0.03 & $\mathrm{C} \mathrm{mol}$ \\
\hline Temperature & $\mathrm{T}$ & 310 & $\mathrm{~Pa}^{-1}$ \\
\hline Faraday & $F$ & 96,485 & $\mathrm{~m}^{3} \mathrm{~m}^{-2}$ \\
\hline Absolute compliance constant of $l m$ & $\mu^{l m}$ & $0.250 \mathrm{~d}-2$ & $\# \mathrm{cells} \mathrm{m}^{-2}$ \\
\hline Reference volume of $l i s$ & $V o l^{l i s, r e f}$ & $3.10 \mathrm{~d}-7$ & $\mathrm{~mol} \mathrm{cell}^{-1}$ \\
\hline Cell density & $D^{c e l l}$ & $4.00 \mathrm{~d}+9$ & $3.50 \mathrm{~d}-13$ \\
\hline Nondiffusible anions in cell & $M_{A}$ & & \\
\hline
\end{tabular}

$o$ outside (luminal) compartment, $i$ inside (serosal) compartment, am apical membrane, $I m$ lateral membrane, $s m$ serosal membrane, $l m$ lateral membrane, $t j$ tight junctions, $i b m$ interspace basement membrane

\section{References}

Agre P, Christensen EI, Smith BL, Nielsen S (1993a) Distribution of the aquaporin CHIP in secretory and resorptive epithelia and capillary endothelia. Proc Natl Acad Sci U S A 90: 7275-7279

Agre P, Knepper MA, Christensen EI, Smith BL, Nielsen S (1993b) CHIP28 water channels are localized in constitutively water-permeable segments of the nephron. J Cell Biol 120:371-383

Altenberg GA, Reuss L (2013) Mechanisms of water transport across cell membranes and epithelia. In: Alpern RJ, Caplan M, Moe OW (eds) Seldin and Giebisch's the kidney. Physiology and pathophysiology. Elsevier/Academic Press, London, pp 95-120

Amerongen HM, Mack JA, Wilson JM, Neutra MR (1989) Membrane domains of intestinal epithelial-cells - distribution of $\mathrm{Na}^{+}, \mathrm{K}^{+}$-ATPase and the membrane skeleton in adult-rat intestine during fetal development and after epithelial isolation. J Cell Biol 109:2129-2138

Andreoli TE, Schafer JA (1979) External solution driving forces for isotonic fluid absorption in proximal tubules. Fed Proc 38:154-160

Bennett CM, Clapp JR, Berliner RW (1967) Micropuncture study of proximal and distal tubule in dog. Am J Physiol 213:1254

Berridge MJ, Oschmann JL (1972) Transporting epithelia. Academic Press, New York/London, pp $1-91$

Borgnia M, Nielsen S, Engel A, Agre P (1999) Cellular and molecular biology of the aquaporin water channels. Annu Rev Biochem 68:425-458

Boron WF, Boulpaep EL (1983a) Intracellular pH regulation in the renal proximal tubule of the salamander. Basolateral $\mathrm{HCO}_{3}{ }^{-}$transport. J Gen Physiol 81:53-94 
Boron WF, Boulpaep EL (1983b) Intracellular pH regulation in the renal proximal tubule of the salamander. Na-H exchange. J Gen Physiol 81:29-52

Boron WF, Boulpaep EL (2017) Medical physiology, 3rd edn. Elsevier, Philadelphia

Burg M, Patlak C, Green N, Villey D (1976) Organic solutes in fluid absorption by renal proximal convoluted tubules. Am J Physiol 231:627-637

Carpi-Medina P, Whittembury G (1988) Comparison of transcellular and transepithelial water osmotic permeabilities $\left(\mathrm{P}_{\mathrm{os}}\right)$ in the isolated proximal straight tubule (PST) of the rabbit kidney. Pflugers Arch 412:66-74

Carpi-Medina P, Gonzáles E, Whittembury G (1983) Cell osmotic water permeability of isolated rabbit proximal convoluted tubules. Am J Physiol 244:F554-F563

Carpi-Medina P, Lindemann B, Gonzáles E, Whittembury G (1984) The continuous measurement of tubular volume changes in response to step changes in contraluminal osmolarity. Pflugers Arch 400:343-348

Cassola AC, Mollenhauer M, Frömter E (1983) The intracellular chloride activity of rat kidney proximal tubular cells. Pflugers Arch 399:259-265

Curran PF (1960) Na, Cl, and water transport by rat ileum in vitro. J Gen Physiol 43:1137-1148

De Weer P, Gadsby DC, Rakowski RF (1988) Voltage dependence of the Na-K pump. Annu Rev Physiol 50:225-241

Diamond JM (1964) Transport of salt and water in rabbit and guinea pig gallbladder. J Gen Physiol 48:1-14

Diamond JM, Bossert WH (1967) Standing-gradient osmotic flow. A mechanism for coupling of water and solute transport in epithelia. J Gen Physiol 50:2061-2083

DiBona DR, Mills JW (1979) Distribution of $\mathrm{Na}^{+}$- pump sites in transporting epithelia. Fed Proc 38:134-143

Dørup J, Maunsbach AB (1997) Three-dimensional organization and segmental ultrastructure of the rat proximal tubules. Exp Nephrol 5:305-317

Edelman A, Curci S, Samarzija I, Fromter E (1978) Determination of intracellular $\mathrm{K}^{+}$activity in rat-kidney proximal tubular cells. Pflugers Arch 378(1):37-45

Eskesen K, Ussing HH (1985) Determination of the electromotive force of active sodium transport in frog skin epithelium (Rana temporaria) from presteady-state flux ratio experiments. J Membr Biol 86:105-111

Ferreira KTG, Ferreira HG (1981) The regulation of volume and ion composition in frog skin. Biochim Biophys Acta 646:193-202

Finkelstein A (1987) Water movement through lipid bilayer, pores, and plasma membranes. Theory and reality. Wiley, New York/Chisester/Brisbane/Toronto/Singapore, pp 1-228

Fischbarg J (2010) Fluid transport across leaky epithelia: central role of the tight junction and supporting role of aquaporins. Physiol Rev 90:1271-1290

Frizzell RA, Field M, Schultz SG (1979) Sodium-coupled chloride transport by epithelial tissues. Am J Physiol 236:F1-F8

Fromm M, Piontek J, Rosenthal R, Gunzel D, Krug SM (2017) Tight junctions of the proximal tubule and their channel proteins. Pflugers Arch 469:877-887

Frömter E (1979) The Feldberg lecture 176: solute transport across epithelia: what can we learn from micropuncture studies on kidney tubules? J Physiol 288:1-31

Frömter E (1982) Electrophysiological analysis of rat renal sugar and amino acid transport. I. Basic phenomena. Pflugers Arch 393:179-189

Gadsby DC, Nakao M (1989) Steady-state current-voltage relationship of the $\mathrm{Na} / \mathrm{K}$ pump in guinea-pig ventricular myocytes. J Gen Physiol 94:511-537

Gaeggeler HP, Guillod Y, Loffing-Cueni D, Loffing J, Rossier BC (2011) Vasopressin-dependent coupling between sodium transport and water flow in a mouse cortical collecting duct cell line. Kidney Int 79:843-852

Garay RP, Garrahan PJ (1973) The interaction of sodium and potassium with the sodium pump in red cells. J Physiol 231:297-325

Garg LC, Knepper MA, Burg MB (1981) Mineralocorticoid effects on Na-K-ATPase in individual nephron segments. Am J Physiol 240:F536-F544 
Ghezzi C, Loo DDF, Wright EM (2018) Physiology of renal glucose handling via SGLT1, SGLT2 and GLUT2. Diabetologia 61:2087-2097

Gögelein H, Greger R (1986) $\mathrm{Na}^{+}$selective channels in the apical membrane of rabbit late proximal tubules (pars recta). Pflugers Arch 406:198-203

Goldin SM (1977) Active transport of sodium and potassium ions by the sodium and potassium ion-activated adenosine triphosphatase from renal medulla. Reconstitution of the purified enzyme into a well defined in vitro transport system. J Biol Chem 252:5630-5642

Goldman DE (1943) Potential, impedance, and rectification in membranes. J Gen Physiol 27:37-60

Gonzáles E, Carpi-Medina P, Linares H, Whittembury G (1984) Osmotic water permeability of the apical membrane of proximal straight tubular (PST) cells. Pflugers Arch 402:337-339

Gottschalk CW (1963) Renal tubular function - lessons from micropuncture. Harvey Lect 58: 99-124

Green R, Giebisch G, Unwin R, Weinstein AM (1991) Coupled water transport by rat proximal tubule. Am J Physiol 261:F1046-F1054

Gyory AZ, Kinne R (1971) Energy source for transepithelial sodium transport in rat renal proximal tubules. Pflugers Arch 327:234-260

Hall JE (2016) Guyton and Hall textbook of medical physiology. Philadelphia, PA, Elsevier

Hertz G (1922) Ein neues Verfahren zur Trennung von Gasgemischen durch Diffusion. Phys Z 23:433-434

Hodgkin AL (1958) The Croonian lecture: ionic movements and electrical activity in giant nerve fibres. Proc R Soc Lond B Biol Sci 148:1-37

Hodgkin AL, Katz B (1949) The effect of sodium ions on the electrical activity of the giant axon of the squid. J Physiol 108:37-77

Hodgkin AL, Keynes RD (1955) Active transport of cations in giant axons from Sepia and Loligo. J Physiol 128:28-66

Hummel CS, Lu C, Loo DD, Hirayama BA, Voss AA, Wright EM (2011) Glucose transport by human renal $\mathrm{Na}^{+} / \mathrm{D}$-glucose cotransporters SGLT1 and SGLT2. Am J Physiol 300:C14-C21

Jørgensen PL (1980) Sodium and potassium ion pump in kidney tubules. Physiol Rev 60:864-917

Jørgensen PL (1986) Structure, function and regulation of Na,K-ATPase in the kidney. Kidney Int 29:10-20

Karniski LP, Aronson PS (1987) Anion-exchange pathways for $\mathrm{Cl}^{-}$transport in rabbit renal microvillus membranes. Am J Physiol 253:F513-F521

Kashgarian M, Biemesderfer D, Caplan M, Forbush B III (1985) Monoclonal antibody to Na, K-ATPase: immunocytochemical localization along nephron segments. Kidney Int 28:899-913

Kirk KL, Schafer JA, DiBona DR (1987) Cell volume regulation in rabbit proximal straight tubule perfused in vitro. Am J Physiol 252:F922-F932

Kokko JP, Burg MB, Orloff J (1971) Characteristics of $\mathrm{NaCl}$ and water transport in renal proximal tubule. J Clin Investig 50:69

Lapointe JY, Duplain M (1991) Regulation of basolateral membrane potential after stimulation of $\mathrm{Na}^{+}$transport in proximal tubules. J Membr Biol 120:165-172

Larsen EH (1973) Effect of amiloride, cyanide and ouabain on the active transport pathway in toad skin. In: Transport Mechanisms in Epithelia, Proc Alfred Benzon Symp, vol V. Munksgaard, Copenhagen, pp 131-147

Larsen EH (1991) Chloride transport by high-resistance heterocellular epithelia. Physiol Rev 71: $235-283$

Larsen EH (2011) Reconciling the Krogh and Ussing interpretations of epithelial chloride transport presenting a novel hypothesis for the physiological significance of the passive cellular chloride uptake. Acta Physiol 202:435-464

Larsen EH, Sørensen JB, Sørensen JN (2000) A mathematical model of solute coupled water transport in toad intestine incorporating recirculation of the actively transported solute. J Gen Physiol 116:101-124

Larsen EH, Sørensen JB, Sørensen JN (2002) Analysis of the sodium recirculation theory of solutecoupled water transport in small intestine. J Physiol 542:33-50

Larsen EH, Willumsen NJ, Møbjerg N, Sørensen JN (2009) The lateral intercellular space as osmotic coupling compartment in isotonic transport. Acta Physiol 195:171-186 
Läuger P (1991) Electrogenic ion pumps. Sinauer Associates, Sunderland, pp 1-313

Layton AT, Vallon V, Edwards A (2015) Modeling oxygen consumption in the proximal tubule: effects of NHE and SGLT2 inhibition. Am J Physiol 308:F1343-F1357

Lew VL, Ferreira HG, Moura T (1979) The behavior of transporting epithelial cells. I. Computer analysis of a basic model. Proc R Soc Lond B Biol Sci 206:53-83

Maunsbach AB (1966) Observations on the segmentation of the proximal tubule in the rat kidney. Comparison of results from phase contrast, fluorescence and electron microscopy. J Ultrastruct Res 16:239-258

Maunsbach AB (1973) Ultrastructure of the proximal tubule. In: Orloff J, Berliner RW (eds) Handbook of physiology. American Physiological Society, Washington, DC, pp 31-79

Maunsbach AB, Boulpaep EL (1991) Immunoelectron microscope localization of Na,K-ATPase in transport pathways in proximal tubule epithelium. Micron Microsc Acta 22:55-56

Mills JW, DiBona DR (1977) On the distribution of $\mathrm{Na}^{+}$-pump sites in the frog skin. J Cell Biol 75: 968-973

Mills JW, DiBona DR (1978) Distribution of $\mathrm{Na}^{+}$-pump sites in the frog gallbladder. Nature 271: 273-275

Mills JW, Ernst SA, DiBona DR (1977) Localization of $\mathrm{Na}^{+}$-pump sites in frog skin. J Cell Biol 73: $88-110$

Morel F, Murayama Y (1970) Simultaneous measurement of undirectional and net sodium fluxes in microperfused rat proximal tubules. Pflügers Arch 320:1-23

Murer H, Hopfer U, Kinne R (1976) Sodium/proton antiport in brush-border-membrane vesicles isolated from rat small intestine and kidney. Biochem J 154:597-604

Nagel W (1980) Rheogenic sodium transport in a tight epithelium, the amphibian skin. J Physiol 302:281-295

Nedergaard S, Larsen EH, Ussing HH (1999) Sodium recirculation and isotonic transport in toad small intestine. J Membr Biol 168:241-251

Nielsen R, Larsen EH (2007) Beta-adrenergic activation of solute coupled water uptake by toad skin epithelium results in near-isosmotic transport. Comp Biochem Physiol A Mol Integr Physiol 148A:64-71

Nielsen S, Kishore BK, Chou C-L, Mandon B, Marples D, Ecelbarger A, Terris J, Wade JB, Knepper MA (1996) Renal aquaporins. Kidney Int 49:1712-1717

Padilla-Benavides T, Roldán ML, Larre I, Flores-Benitez D, Villegas-Sepúlveda N, Contreras RG, Cereijido M, Shoshani L (2010) The polarized distribution of $\mathrm{Na}^{+}, \mathrm{K}^{+}$-ATPase: role of the interaction between $\beta$ subunits. Mol Biol Cell 21(13):2217-2225

Parent L, Supplisson S, Loo DDF, Wright EM (1992) Electrogenic properties of the cloned $\mathrm{Na}^{+}$/glucose cotransporter: I. Voltage-clamp studies. J Membr Biol 125:49-62

Parsons DS, Wingate DL (1958) Fluid movements across the wall of rat small intestine in vitro. Biochim Biophys Acta 30:666-667

Reuss L (1985) Changes in cell volume measured with an electrophysiologic technique. Proc Natl Acad Sci U S A 82:6014-6018

Sackin H, Boulpaep EL (1975) Models for coupling of salt and water transport. Proximal tubular reabsorption in necturus kidney. J Gen Physiol 66:671-733

Samarzija I, Hinton BT, Fromter E (1982) Electrophysiological analysis of rat renal sugar and amino acid transport II. Dependence on various transport parameters and inhibitors. Pflugers Arch 393(2):190-197

Sardet C, Franchi A, Pouyssegur J (1989) Molecular cloning, primary structure, and expression of the human growth factor-activatable $\mathrm{Na}^{+} / \mathrm{H}^{+}$antiporter. Cell 56:271-280

Schafer JA (1990) Transepithelial osmolality differences, hydraulic conductivities, and volume absorption in the proximal tubule. Annu Rev Physiol 52:709-726

Schafer JA (1993) The rat collecting duct as an isosmotic volume reabsorber. In: Ussing HH, Fischbarg J, Sten-Knudsen O, Larsen EH, Willumsen NJ (eds) Proceeding of alfred benzon symposium 34. Isotonic transport in leaky epithelia. Munksgaard, Copenhagen, pp 339-354

Schafer JA, Troutman SL, Andreoli TE (1974) Volume reabsorption, transepithelial potential differences, and ionic permeability properties in mammalian superficial proximal straight tubules. J Gen Physiol 64:582-607 
Schafer JA, Patlak CS, Troutman SL, Andreoli TE (1978) Volume absorption in the parts recta. II. Hydraulic conductivity coefficient. Am J Physiol 234:F340-F348

Schatzmann HJ, Windhager EE, Solomon AK (1958) Single proximal tubules of the Necturus kidney. II. Effect of 2, 4-dinitro-phenol and ouabain on water reabsorption. Am J Physiol 195(3):570-574

Schnermann J, Chou C-L, Ma T, Traynor T, Knepper MA, Verkman AS (1998) Defective proximal tubular fluid reabsorption in transgenic aquaporin-1 null mice. Proc Natl Acad Sci U S A 95: 9660-9664

Schultz SG (1980) The electrochemical potential. In: Hutchinson F, Fuller W, Mullins LJ (eds) Basic principles of membrane transport. Cambridge University Press, Cambridge, pp 8-13

Skou JC (1965) Enzymatic basis for active transport of $\mathrm{Na}^{+}$and $\mathrm{K}^{+}$across cell membrane. Physiol Rev 45:596-617

Smoluchowski MV (1915) Über Brownsche Molekularbewegung unter Einwirkung äusserer Kräfte und derem Zusammenhang mit der verallgemeinerten Diffusionsgleichung. Ann Phys 48:1103-1112

Spring KR (1999) Epithelial fluid transport - a century of investigation. News Physiol Sci 14:92-98

Spring KR, Hope A (1978) Size and shape of the lateral intercellular spaces in a living epithelium. Science 200:54-57

Spring KR, Kimura G (1978) Chloride reabsorption by renal proximal tubules of Necturus. J Membr Biol 38:233-254

Spring KR, Kimura G (1979) Intracellular ion activities in Necturus proximal tubule. Fed Proc 38:2729-2732

Stein WD (1967) The movement of molecules across cell membranes. Academic Press, New York, pp 1-369

Sten-Knudsen O (2002) Biological membranes. Theory of transport, potentials and electric impulses. Cambridge University Press, Cambridge, pp 1-671

Sten-Knudsen O, Ussing HH (1981) The flux ratio equation under nonstationary conditions. J Membr Biol 63:233-242

Stirling CE (1972) Radioautographic localization of sodium pump sites in rabbit intestine. J Cell Biol 53:704-714

Thomas RC (1972) Electrogenic sodium pump in nerve and muscle cells. Physiol Rev 52:563-594

Tripathi S, Boulpaep EL (1989) Mechanisms of water transport by epithelial cells. Q J Exp Physiol 74:385-417

Turner RJ, Moran A (1982) Heterogeneity of sodium-dependent D-glucose transport sites along the proximal tubule - evidence from vesicle studies. Am J Physiol 242:F406-F414

Turner RJ, Silverman M (1977) Sugar uptake into brush-border vesicles from normal human kidney. Proc Natl Acad Sci U S A 74:2825-2829

Ullrich KJ (ed) (1973) Permeability characteristics of the mammalian nephron. American Physiological Society, Bethesda

Ussing HH (1985) Volume regulation and basolateral co-transport of sodium, potassium, and chloride ion in frog skin epithelium. Pflugers Arch 405(suppl 1):S2-S7

Warnock DG, Lucci MS (1979) Effect of anion-transport inhibitors on $\mathrm{NaCl}$ reabsorption in the rat superficial proximal convoluted tubule. J Clin Investig 64:570-579

Weinstein AM (1985) Glucose-transport in a model of the rat proximal tubule epithelium. Math Biosci 76:87-115

Weinstein AM (1986) A mathematical model of the rat proximal tubule. Am J Physiol 250: F860-F873

Weinstein AM (1992) Chloride transport in a mathematical model of the rat proximal tubule. Am J Physiol 263:F784-F798

Weinstein AM (2013) Sodium and chloride transport: proximal nephron. In: Alpern RJ, Moe OW, Caplan MJ (eds) Seldin and Giebisch's the kidney. Elsevier, Amsterdam, pp 1081-1141

Weinstein AM, Stephenson JL (1979) Electrolyte transport across a simple epithelium. Steady-state and transient analysis. Biophys J 27:165-186

Weinstein AM, Stephenson JL (1981) Models of coupled salt and water transport across leaky epithelia. J Membr Biol 60:1-20 
Welling LW, Grantham JJ (1972) Physical properties of isolated perfused renal tubules and tubular basement membranes. J Clin Investig 51:1063-1075

Welling LW, Welling DJ (1975) Surface areas of brush border and lateral cell walls in the rabbit proximal nephron. Kidney Int 8:343-348

Welling LW, Welling DJ (1988) Relationship between structure and function in renal proximal tubule. J Electron Microsc Tech 9:171-185

Welling LW, Welling DJ, Holsapple JW, Evan AP (1987a) Morphometric analysis of distinct microanatomy near the base of proximal tubule cells. Am J Physiol 253:F126-F140

Welling LW, Welling DJ, Ochs TJ (1987b) Video measurement of basolateral $\mathrm{NaCl}$ reflection coefficient in proximal tubule. Am J Physiol 253:F290-F298

Whittembury G, Reuss L (1992) Mechanisms of coupling of solute and solvent transport in epithelia. In: Seldin DW, Giebisch G (eds) Kidney: physiology and pathophysiology. Raven Press, New York, pp 317-360

Whittembury G, Malnic G, Mello-Aires M, Amorena C (1988) Solvent drag of sucrose during absorption indicates paracellular water flow in the rat kidney proximal tubule. Pflugers Arch 412:541-547

Wilson RW, Wareing M, Green R (1997) The role of active transport in potassium reabsorption in the proximal convoluted tubule of the anaesthetized rat. J Physiol 500:155-164

Windhager EE (1979) Sodium chloride transport. In: Giebisch G, Tosteson DC, Ussing HH (eds) Membrane transport in biology, Transport organs, vol IVA. Springer, Berlin, pp 145-213

Windhager EE, Whittembury G, Oken DE, Schatzmann HJ, Solomon AK (1959) Single proximal tubules of the Necturus kidney. III. Dependence of $\mathrm{H}_{2} \mathrm{O}$ movement on $\mathrm{NaCl}$ concentration. Am J Physiol 197:313-318

Wittekindt OH, Dietl P (2019) Aquaporins in the lung. Pflugers Arch 471(4):519-532

Wu MM, Civan MM (1991) Voltage dependence of current through the Na,K-exchange pump of Rana oocytes. J Membr Biol 121:23-36

Yoshitomi K, Fromter E (1985) How big is the electrochemical potential difference of Na+ across rat renal proximal tubular cell membranes in vivo? Pflugers Arch 405(Suppl 1):S121-S126

Yoshitomi K, Burckhardt BC, Fromter E (1985) Rheogenic sodium-bicarbonate cotransport in the peritubular cell membrane of rat renal proximal tubule. Pflugers Arch 405:360-366

Zeuthen T (2000) Molecular water pumps. Rev Physiol Biochem Pharmacol 141:97-151

Zeuthen T, Meinild AK, Loo DD, Wright EM, Klaerke DA (2001) Isotonic transport by the $\mathrm{Na}^{+}$-glucose cotransporter SGLT1 from humans and rabbit. J Physiol 531:631-644

Zhuo JL, Li XC (2013) Proximal nephron. Compr Physiol 3:1079-1123

Zurzolo C, Rodriguezboulan E (1993) Delivery of $\mathrm{Na}^{+}, \mathrm{K}^{+}$-ATPase in polarized epithelial-cells. Science 260:550-552

Open Access This chapter is licensed under the terms of the Creative Commons Attribution 4.0 International License (http://creativecommons.org/licenses/by/4.0/), which permits use, sharing, adaptation, distribution and reproduction in any medium or format, as long as you give appropriate credit to the original author(s) and the source, provide a link to the Creative Commons licence and indicate if changes were made.

The images or other third party material in this chapter are included in the chapter's Creative Commons licence, unless indicated otherwise in a credit line to the material. If material is not included in the chapter's Creative Commons licence and your intended use is not permitted by statutory regulation or exceeds the permitted use, you will need to obtain permission directly from the copyright holder.

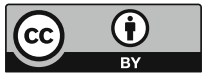

